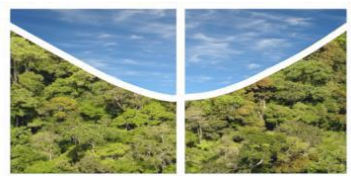

Universidade de Brasília

Instituto de Ciências Biológicas

Programa de Pós-Graduação em Zoologia

INVESTIGAÇÕES SOBRE O PAR MIMÉTICO SIDERONE GALANTHIS

E CALLICORE SORANA (LEPIDOPTERA, NYMPHALIDAE) EM ÁREAS DE CERRADO SENSU STRICTO DO BRASIL CENTRAL

Wesley Silveira Rocha

Brasília - DF 
Universidade de Brasília

Instituto de Ciências Biológicas

Programa de Pós-Graduação em Zoologia

\title{
INVESTIGAÇÕES SOBRE O PAR MIMÉTICO SIDERONE GALANTHIS E CALLICORE SORANA (LEPIDOPTERA, NYMPHALIDAE) EM ÁREAS DE CERRADO SENSU STRICTO DO BRASIL CENTRAL
}

\author{
Wesley Silveira Rocha
}

Orientador: Dr. Carlos Eduardo Guimarães Pinheiro

Dissertação apresentada ao Programa de Pós-Graduação em Zoologia da Universidade de Brasília, como requisito parcial para a obtenção do título de Mestre em Zoologia.

Brasília - DF 


\section{Universidade de Brasilia}

Dissertação de Mestrado

\section{WESLEY SILVEIRA ROCHA}

Título:

"Investigações sobre o par mimético Siderone galanthis e Callicore sorana (Lepidoptera, Nymphalidae) em áreas de cerrado sensu stricto do Brasil central".

Banca Examinadora:

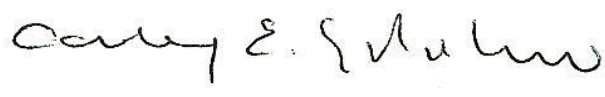

Prof. Dr. Carlos Eduardo Guimarães Pinheiro

Presidente/ Orientador $\mathrm{ZOO} / \mathrm{UnB}$

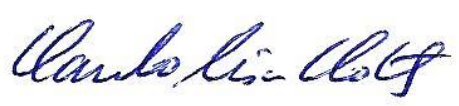

Prof. Dr. Paulo César Motta

Membro Titular ZOO/UnB

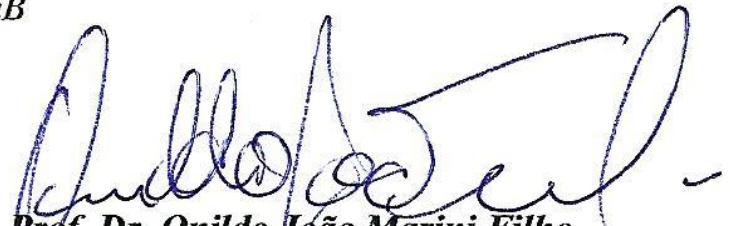
erof. Dr. Onildo Lỗo Marini Filho Membro Titular Instituto Chico Mendes/ICMBio 
Dedico este trabalho a Deus e aos meus pais que tanto apoiaram e incentivaram o meu aprimoramento profissional. 


\section{AGRADECIMENTOS}

Agradeço primeiramente a DEUS, por sua proteção, cuidado e força que foram primordiais para que não me abalasse mesmo em momentos de desânimo e desespero.

Ao prof. Dr. Carlos Eduardo Guimarães Pinheiro, pelo acolhimento, amizade e confiança, compartilhando comigo suas valiosas experiências de vida e permitindo ampliar meus horizontes de conhecimento, a minha eterna gratidão.

Aos membros da banca Dr. Paulo César Motta, Dr. Onildo Marini-Filho e Dra. Marina Frizzas pelas valiosas críticas e sugestões acerca desta tese.

Aos funcionários da Fazenda Água Limpa - UnB, em especial aos vigias e porteiros pelos longos bate-papos nos fins de semana de campo e pela prestreza em sempre me ajudar quando precisei.

Aos professores do Programa de Pós - Graduação em Zoologia pelos ensinamentos e trocas de experiências durante as disciplinas que foram de grande valia para minha formação profissional.

À minha mãe Edna e meu pai Edmilson, por sua dedicação, cuidado e segurança que me deram ao longo dessa etapa de minha vida, me apoiando sempre!

À minha irmã Danielle e meu cunhado Daniel que mesmo distantes de mim mandaram energias positivas, orações e incentivos para que eu concluísse com êxito esta jornada. Em especial ao mais novo membro da família, meu sobrinho "Vitinho", que em breve estará conosco.

Aos colegas e funcionários (professores, técnicos e alunos) do Departamento de Ecologia pelo apoio, sugestões e amizade, em especial aos técnicos: Leandro Faleiros, Maria Regina Sartori, Izabelly Santana, Maria do Desterro e Mardônio Timo pela compreensão e companheirismo no ambiente de trabalho.

Aos meus amigos Vitor César, Reile Rossi e Neuza Aparecida pela companhia durante as disciplinas e parceria em muitos trabalhos que fizemos durante o mestrado.

Aos meus amigos de longa data: Rodrigo Cardoso, Renata Miranda, Jaqueline Lamounier, Thais Torquato e Maria do Socorro que sempre me apoiaram e me incentivaram.

A todos aqueles (as) que participaram de alguma forma para a concretização deste sonho, o meu muito obrigado! 
"Talvez não tenha conseguido fazer o melhor, mas lutei para que o melhor fosse feito. Não sou o que deveria ser, mas Graças a Deus, não sou o que era antes".

Martin Luther King 


\section{RESUMO}

Neste estudo foram investigadas as características populacionais, a palatabilidade e as relações miméticas entre Siderone galanthis e Callicore sorana em uma área de cerrado sensu stricto no Brasil central. Os resultados obtidos mostraram que estas espécies exibem um padrão de dinâmica populacional bastante semelhante entre si, com ambas as espécies ocorrendo durante a estação seca (abril a setembro) e atingindo picos populacionais em agosto em 2014 e 2015. Além disto, ambas as espécies mostraram fortes semelhanças nos tamanhos populacionais, no tempo de residência na área de estudos e padrões de dispersão. Experimentos de palatabilidade conduzidos com aranhas (Nephila clavipes) e lagartos (Tropidurus itambere) não indicaram a presença de compostos químicos defensivos, sugerindo que ambas as espécies são palatáveis para predadores. Estes resultados sugerem que Siderone galanthis e Callicore sorana não constituem um caso clássico de mimetismo Batesiano ou Mülleriano, mas podem constituir um caso de mimetismo de escape. Esta possibilidade também é sugerida pela grande quantidade de marcas de bicadas de aves encontradas nas asas destas borboletas, que indica que foram fortemente atacadas, mas escaparam dos ataques de aves insetívoras. Uma tentativa para testar a vantagem do mimetismo para estas borboletas em condições naturais, independentemente do tipo de mimetismo envolvido entre elas, também é apresentada.

Palavras-chaves: Callicore sorana; mimetismo Batesiano; mimetismo de escape; mimetismo Mülleriano; palatabilidade; populacão; Siderone galanthis. 


\begin{abstract}
This study investigates some population traits, the palatability, and the mimetic relationship between Siderone galanthis and Callicore sorana in a site of cerrado sensu stricto in central Brazil. The results obtained showed that these butterflies exhibit a very similar population dynamics with both species occurring during the dry season (April to September) and reaching peak numbers in August in both 2014 and 2015 censuses. In addition, both butterflies showed similar population sizes, longevity (residence in the study site), and dispersal patterns. Palatability experiments conducted with spiders (Nephila clavipes) and lizards (Tropidurus itambere) did not indicate the presence of defensive chemicals, suggesting that both butterflies are palatable to predators. These results indicate that Siderone galanthis and Callicore sorana do not constitute a classic case of Batesian or Müllerian mimicry, but rather a case of escape mimicry. Such a possibility is supported by a large number of bird beak marks found on the wings of live butterflies, which indicate they were heavily attacked by escaped attacks of insectivorous birds. An attempt to test the advantage of mimicry for these butterflies in natural conditions, regardless the type of mimicry involved between them, is also reported.
\end{abstract}

Keywords: Callicore sorana; Batesian mimicry; escape mimicry; Müllerian mimicry; palatability; population; Siderone galanthis. 


\section{LISTA DE FIGURAS}

FIGURA 1. Aposematismo e camuflagem em borboletas. A) e C) são indivíduos de $S$. galanthis e C. sorana mostrando a face crípitica, respectivamente; B) e D) são indivíduos de $S$. galanthis e $C$. sorana mostrando a face aposemática. Fotos: WS Rocha e CP Camargo.

FIGURA 2. Mapa de localização da área de estudo na Fazenda Água Limpa - FAL/UnB, indicando as três subáreas (A, B e C) onde os experimentos foram conduzidos. Fonte: Google Earth 2015 .

FIGURA 3. Desenho esquemático da área de estudo. A) Metragem das subáreas e disposição das armadilhas, B) Armadilha Van Someren-Rydon contendo ísca atrativa; C) Visão geral da vegetação de cerrado sensu stricto localizada nas áreas de estudo. Fotos: WS Rocha.

FIGURA 4. Marcação numérica na face ventral da asa anterior: A) S. galanthis; B) $C$. sorana. Foto: WS Rocha.

FIGURA 5. Alteração do padrão de coloração das asas de $S$. galanthis. A) Vista dorsal, não alterada (grupo controle); B), vista dorsal, alterada (grupo alterado). Fotos: WS Rocha.

FIGURA 6. Tempo médio de residência de machos e fêmeas de $S$. galanthis e $C$. sorana durante o período de estudo. O número de indivíduos recapturados (n) e o tempo máximo de residência encontrado são também apresentados

FIGURA 7. Estimativas de tamanhos populacionais de $S$. galanthis e $C$. sorana nos anos de 2014 e 2015 com seus respectivos erros padrões.

FIGURA 8. Média das distâncias lineares percorridas $(\bar{X}+D P)$ entre sucessivas capturas de indivíduos de $S$. galanthis e $C$. sorana na área de estudo. O número de deslocamentos (n) e as distâncias máximas percorridas (em metros) são também apresentados

FIGURA 9. Frequência de recapturas de indivíduos na mesma subárea da captura e em diferentes subáreas de estudo. O número de deslocamentos (n) obtidos para cada 
espécie e sexo também são apresentados. O asterisco indica resultado com significância estatatística $(P<0,05)$.

FIGURA 10. Marcas do tipo "tears". A) marca assimétrica em C. sorana, vista dorsal; B) marca simétrica em S. galanthis, vista dorsal e C) S. galanthis, vista ventral. Fotos: WS Rocha.

FIGURA 11. Proporção de marcas simétricas e assimétricas encontradas em machos e fêmeas de $S$. galanthis e $C$. sorana. O número de marcas (n) encontrado é apresentado. O asterisco indica resultado com significância estatística $(P<0,05)$.

FIGURA 12. Média de marcas de bicadas simétricas por sexo e idade ( $\mathrm{J}=$ jovem, $\mathrm{I}=$ intermediário e V= velho) em $S$. galanthis e $C$. sorana. O número de indivíduos em cada classe etária (n) também é apresentado.

FIGURA 13. Média de marcas de bicadas assimétricas por sexo e idade ( $J=$ jovem, $I=$ intermediário e V= velho) em $S$. galanthis e $C$. sorana. O número de indivíduos em cada faixa etária (n) também é apresentado.

FIGURA 14. Teste de palatabilidade com Nephila clavipes. A) Fêmea de Nephila clavipes (maior) ao lado de um macho (menor); B) N. clavipes predando S. galanthis; C) N. clavipes predando C. sorana. Fotos: WS Rocha. 36

FIGURA 15. Teste de palatabilidade com Tropidurus itambere. A) Indivíduo de T. itambere; B) T. itambere predando C. sorana; C) T. itambere predando S. galanthis. Fotos: WS Rocha.

FIGURA 16. Número médio de marcas de bicadas encontradas em indivíduos de S. galanthis com padrões de cores não alterados e alterados. O número de indivíduos recapturados (n) e os desvios padrões são também apresentados 


\section{LISTA DE TABELAS}

TABELA 1. Número de indivíduos marcados e taxas de recaptura durante o período de julho a outubro de 2014 e junho a setembro de 2015.

TABELA 2. Razões sexuais encontradas para $S$. galanthis e $C$. sorana na área de estudo nos anos de 2014 e 2015 . Valores de $X^{2}$ comparam os resultados obtidos com uma razão sexual de 1:1. Todos os testes com 1 g.l.

TABELA 3. Tempo de residência de machos e fêmeas de $S$. galanthis e $C$. sorana recapturados durante o estudo. O número de indivíduos (n) e testes de MannWhitney são também apresentados.

TABELA 4. Comparações das distâncias lineares percorridas por indivíduos de S. galanthis e C. sorana entre sucessivas recapturas. O número de indivíduos (n) e os valores do teste $t$ são também apresentados.

TABELA 5. Frequência de recapturas de indivíduos na mesma subárea da captura original e em diferentes subáreas de estudo. O número de deslocamentos (n) obtidos para cada espécie e sexo, os valores do teste $\mathrm{G}$ (Williams) são apresentados. 30

TABELA 6. Número e porcentagem de machos e fêmeas de $S$. galanthis e $C$. sorana apresentando ou não marcas de bicadas e as comparações realizadas com o teste de $X^{2}$ (todos os testes com 1 g.1.).

TABELA 7. Número de marcas simétricas e assimétricas encontradas em machos e fêmeas de $S$. galanthis e $C$. sorana e as comparações realizadas através de teste $X^{2}$.

TABELA 8. Comparações da média de marcas de bicadas assimétricas entre indivíduos do mesmo sexo e idade (J= jovem, I= intermediário e V= velho) de $S$. galanthis e $C$. sorana. O número de indivíduos em cada faixa etária (n) e os valores do teste $t$ são também apresentados.

TABELA 9. Número de indivíduos com padrões de coloração alterados e não alterados com suas respectivas taxas de recapturas.

TABELA 10. Tempo médio de residência $(\bar{X} \pm$ DP) de indivíduos com padrões de coloração alterados e não alterados (n). 


\section{SUMÁRIO}

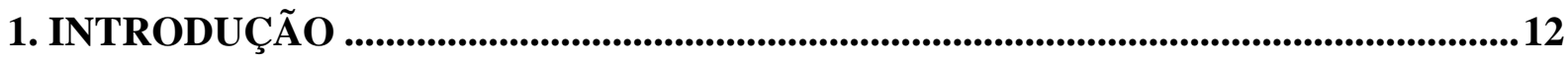

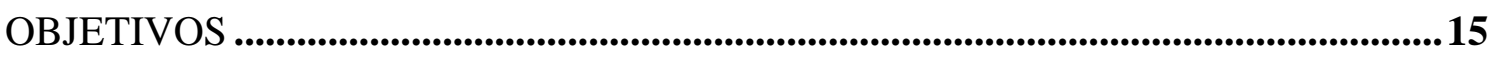

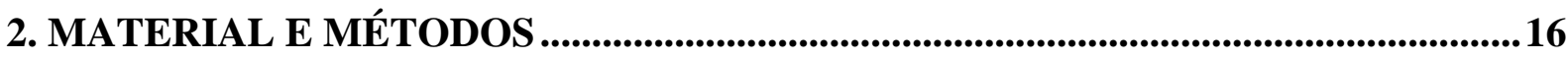

2.1 Espécies estudadas .......................................................................................................16

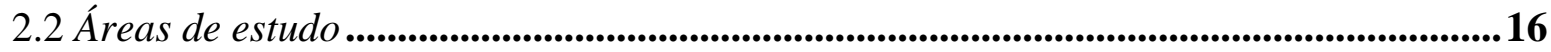

2.3 Métodos de Campo ................................................................................................18

2.4 Estimativas de Tamanhos Populacionais ...............................................................19

2.5 Testes de palatabilidade ......................................................................................................20

2.5.1 Experimentos com Nephila clavipes ..................................................................21

2.5.2 Experimentos com Tropidurus itambere ..................................................................21

2.6 Experimento sobre a vantagem do mimetismo em condições naturais ............................22

2.7 Testes Estatísticos ....................................................................................................23

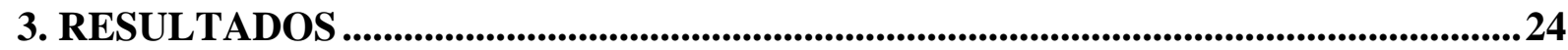

3.1 Números de animais marcados, recapturados, razões sexuais e tempo de residência ..24

3.2 Tamanhos populacionais .....................................................................................................................22

3.3 Dispersão de indivíduos nas áreas de estudos ..................................................................28

3.4 Sinais de ataques de predadores (marcas de bicadas) ....................................................31

3.5 Testes de palatabilidade .................................................................................................................36

3.6 Experimento sobre a vantagem do mimetismo em condições naturais ...........................38

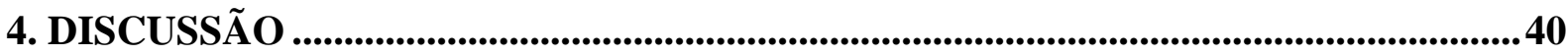

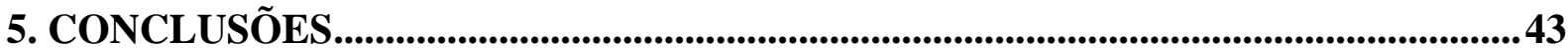

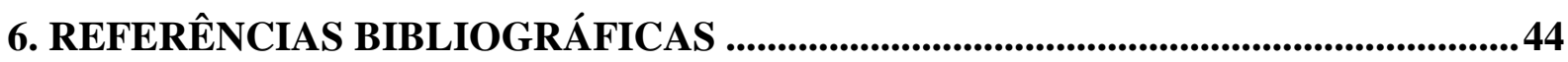




\section{INTRODUÇÃO}

Borboletas (Lepidoptera, Papilionoidea) são insetos diurnos que podem utilizar uma grande variedade de compostos químicos para se defenderem de ataques de aves insetívoras e outros predadores. Entre os compostos que conferem certa impalatabilidade (termo utilizado por Bates em (1862) para caracterizar os "modelos" nas relações miméticas entre borboletas) a essas borboletas encontram-se: cardenolidas, encontrados na conhecida borboleta monarca (Danaini), glicosídeos cianogênicos (Heliconiini e Acraeini), glicosídeos iridóides presentes em Euphydrias, Poladryas (Melitaeini) e Junonia (Junoniini), glicosinolatos (Pierini), alcalóides pirrolozidínicos e tropânicos (Ithomiini, Danaini), ácido aristolóquico (Troidini), pirazinas (vários grupos) e muitos outros compostos ainda pouco conhecidos. Estes compostos químicos podem ser seqüestrados da própria planta hospedeira da qual a larva se alimenta, mas também de várias outras fontes vegetais como flores e frutos, ou serem sintetizadas pelos próprios indivíduos através da chamada síntese "de novo" (Brower, 1984; Bowers, 1993; Trigo, 2000).

De acordo com a teoria do mimetismo Batesiano (Bates, 1862) predadores visualmente orientados como as aves insetívoras aprendem ou associam o gosto ou cheiro ruim destas substâncias, ou ainda os efeitos negativos advindos de sua ingestão, com a sua coloração, e passam a evitar ataques sobre as espécies quimicamente defendidas (modelos) depois de algumas experiências desagradáveis com as mesmas. Outras borboletas que não apresentam defesas químicas (mímicos Batesianos) podem então se defender enganando predadores ao imitar a coloração de borboletas quimicamente defendidas, mas para que isto ocorra é necessário que os predadores encontrem primeiramente os modelos e aprendam a evitá-los antes de encontrarem os mímicos Batesianos. Para isto, Bates e muitos autores adotam como premissa desta teoria que as populações de modelos devem ser maiores de que as populações de mímicos, mas Pinheiro (2007) mostrou um caminho alternativo, baseado nos horários de atividade de modelos e mímicos, que também leva os predadores a encontrarem os modelos antes dos mímicos.

Além do mimetismo Batesiano, borboletas também podem apresentar outros tipos de mimetismo como o Mülleriano, no qual duas ou mais espécies quimicamente defendidas (impalatáveis) convergem em seus padrões de coloração, o que permite acelerar o processo de 
aprendizagem dos predadores e, conseqüentemente, diminuir a taxa de predação sobre cada uma das espécies envolvidas (Müller, 1879), e diferentes formas de mimetismo de escape, onde predadores aprendem a evitar espécies palatáveis, mas com grande capacidade de fugir ou escapar de seus ataques (van Someren \& Jackson, 1959). Neste caso, e por analogia com os tipos clássicos de mimetismo, são reconhecidos o "mimetismo Batesiano de escape", onde uma espécie com grande capacidade de escape (modelo) é imitada por outra espécie palatável (mímico Batesiano), mas com menor capacidade de escapar de ataques de predadores, e o “mimetismo Mülleriano de escape" onde todas as espécies envolvidas apresentam capacidade semelhante de fugir ou escapar de predadores (Pinheiro \& Freitas, 2014). A possibilidade do mimetismo de escape é corroborada por experimentos realizados por Gibson $(1974,1980)$ e por Hancox \& Allen (1991) que demonstram que predadores aprendem a evitar presas que não conseguem capturar. Nem todos os autores, entretanto, aceitam este tipo de mimetismo (ver discussão).

O Brasil é o país com maior diversidade de espécies de borboletas de todo o planeta, sendo que tanto o mimetismo Batesiano quanto o mimetismo Mülleriano foram primeiramente descritos com espécies da fauna brasileira. Apesar de muitos avanços no conhecimento das defesas químicas e na sistemática de espécies Neotropicais, várias interações miméticas entre espécies nunca foram efetivamente testadas em campo e outras permanecem não investigadas. Este é o caso das espécies Callicore sorana (Godart, 1824) e Siderone galanthis (Cramer, 1775) que ocorrem em áreas de cerrado sensu strito do Brasil central (Brown \& Mielke, 1967; Emery et al., 2006 ).

A semelhança de coloração entre essas espécies ocorre especialmente na superfície dorsal das asas onde apresentam manchas vermelhas espalhadas sobre um fundo azul escuro ou negro, o que lhes confere uma aparência semelhante quando em vôo ou pousadas com as asas abertas (Figuras 1B e 1D). Estas cores são bastante chamativas e também encontradas em várias espécies impalatáveis e miméticas como Heliconius erato (Linnaeus, 1764), H. melpomene (Linnaeus, 1758) (Nymphalidae, Heliconiinae) e também nas altamente impalatáveis Parides (Papilionidae, Troidini), que também ocorrem na região do Brasil central (Pinheiro, 1996). Quando pousadas, entretanto, estas espécies exibem a superfície ventral das asas que possuem uma coloração críptica. C. sorana exibe uma coloração semelhante ao tronco das árvores do cerrado onde comumente pousa com as asas fechadas apresentando padrões numéricos no lado ventral das asas posteriores (número "80”) e $S$. 
galanthis apresenta uma forte semelhança com folhas velhas, sendo que além da forma e da cor, também apresenta as nervuras principais da folha (um tipo de coloração críptica que tem recebido o nome de "masquerade" devido à grande similaridade com o substrato natural onde o indivíduo se encontra e a complexidade de eventos envolvidos (Skelhorn et al., 2010) (Figuras 1A e 1C).

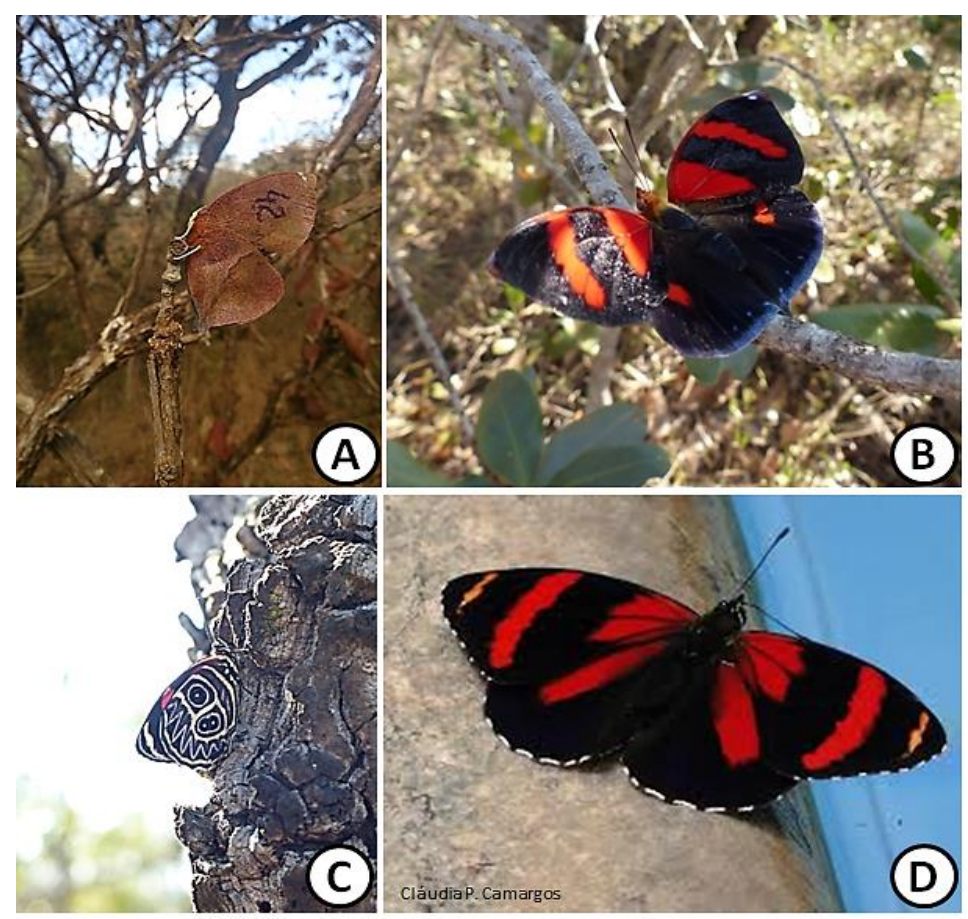

FIGURA 1. Aposematismo e camuflagem em borboletas. A) e C) são indivíduos de $S$. galanthis e $C$. sorana mostrando a face crípitica, respectivamente; B) e D) são indivíduos de $S$. galanthis e $C$. sorana mostrando a face aposemática. Fotos: WS Rocha e CP Camargo.

Estudos prévios sobre a palatabilidade de espécies do gênero Callicore, como Callicore astarte selima (Gueneé, 1872) e Callicore texa maximilla (Fruhstorfer, 1916), realizados na Amazônia oriental (região de Carajás, sul do Pará) mostraram que respectivamente $1 / 5$ e 1/6 das borboletas atacadas e capturadas por Tyrannus melancholicus (Vieillot, 1819) (Aves, Tyrannidae) foram posteriormente rejeitadas (liberadas vivas) pelas aves (Pinheiro \& Martins, 1992; Pinheiro, 1996), indicando certa impalatabilidade neste gênero, mas experimentos com $C$. sorana nunca foram realizados. Este também é o caso de $S$. galanthis, mas experimentos de palatabilidade com outros Charaxinae têm indicado que este grupo é totalmente palatável para seus predadores (Brower, 1984; Srygley \& Chai, 1990; Pinheiro, 1996), sendo que algumas espécies são consideradas mímicos Batesianos de espécies impalatáveis (e.g. Consul fabius (Cramer, 1775) que imita Heliconius ethilla (Godart, 1819) e várias outras borboletas que formam o conhecido anel mimético tigrado) 
(Pinheiro, 1996). Estas características nos levam a supor que C. sorana e S. galanthis constituam um caso clássico de mimetismo Batesiano, com a primeira servindo de modelo para a segunda, mas conforme assinalado acima, outros tipos de mimetismo como o mimetismo Mülleriano ou o mimetismo de escape poderiam também estar envolvidos. Além disto, muitas características populacionais e comportamentais destas espécies permanecem não investigadas.

\section{OBJETIVOS}

1) Investigar as características populacionais de Siderone galanthis e Callicore sorana incluindo: os tamanhos populacionais, as razões sexuais e o tempo de residência de adultos destas espécies;

2) Investigar os padrões de dispersão de adultos destas espécies incluindo o deslocamento de indivíduos recapturados (distância linear em metros) e a probabilidade de recaptura na mesma subárea ou em subáreas diferentes de estudo;

3) Investigar os padrões de ataques dos predadores sobre essas espécies, incluindo a proporção de indivíduos com marca de bicadas (atacados) e o número de marcas simétricas ou não simétricas, que poderiam indicar se os indivíduos foram atacados em pouso ou em vôo;

4) Testar a palatabilidade de $S$. galanthis e $C$. sorana com diferentes predadores naturais;

5) Testar a vantagem do mimetismo no par mimético S. galanthis e C.sorana em condições naturais. 


\section{MATERIAL E MÉTODOS}

\subsection{Espécies estudadas}

Siderone galanthis (Nymphalidae, Charaxinae) e Callicore sorana (Nymphalidae, Biblidinae) são encontradas em diferentes fitofisionomias de cerrado como áreas abertas e matas de galeria, mas são especialmente abundantes no cerrado sensu stricto (Pinheiro \& Ortiz, 1992). Adultos de ambas as espécies se alimentam de frutos em decomposição e são facilmente capturados com armadilhas que usam iscas com frutos fermentados. As larvas $S$. galanthis se alimentam de Casearia sylvestris (Swartz, 1860) (Flacourtiaceae) enquanto C. sorana se alimenta de folhas de Serjania sp. (Sapindaceae) (Diniz \& Morais, 1995), ambas aparentemente bastante comuns no Brasil central.

\section{2 Áreas de estudo}

O trabalho de campo foi conduzido na Fazenda Água Limpa - FAL (4.500 hectares), situada na Área de Proteção Ambiental (APA) Gama e Cabeça de Veado a $30 \mathrm{~km}$ do Plano Piloto, Brasília - DF (1556’S, 4753'W) (Figura 2). A área está situada a $1.100 \mathrm{~m}$ de altitude com uma precipitação anual de $1.600 \mathrm{~mm}$ e uma temperatura média anual variando de 20 a 28 ${ }^{\circ} \mathrm{C}$. O clima da região é caracterizado por estações quentes e úmidas de outubro a março e secas e frias de abril a setembro (Ribeiro \& Walter, 1998). 


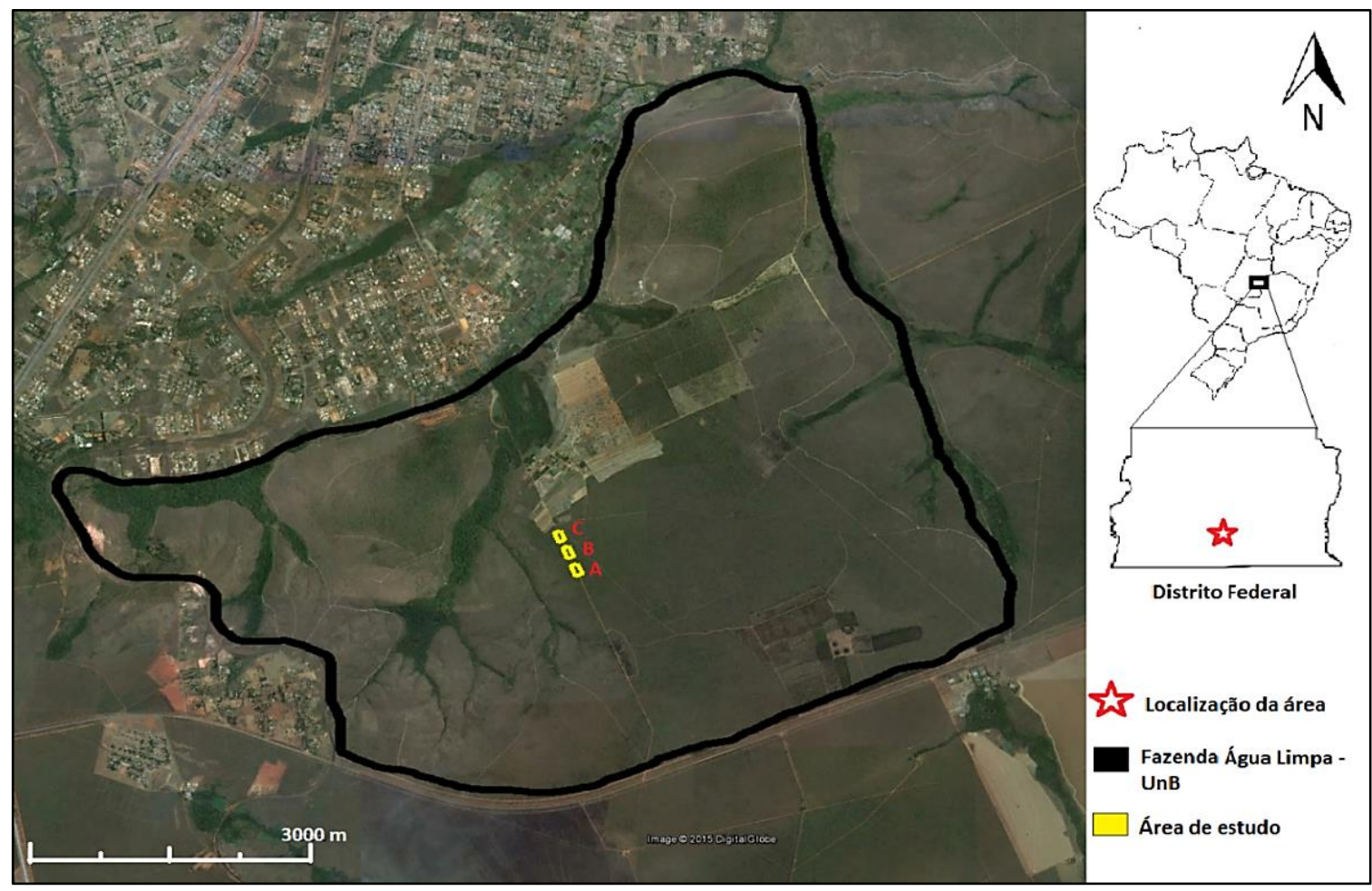

FIGURA 2. Mapa de localização da área de estudo na Fazenda Água Limpa - FAL/UnB, indicando as três subáreas (A, B e C) onde os experimentos foram conduzidos. Fonte: Google Earth 2015.

Foram delimitadas três áreas amostrais em vegetação de cerrado sensu stricto (subáreas A, B e C) onde as espécies envolvidas neste projeto são comumente encontradas (Pinheiro \& Ortiz, 1992) (Figura 3C). Cada subárea possui 120 x 50m (comprimento x largura) e separadas por distâncias de 100 m (Figura 3A). 


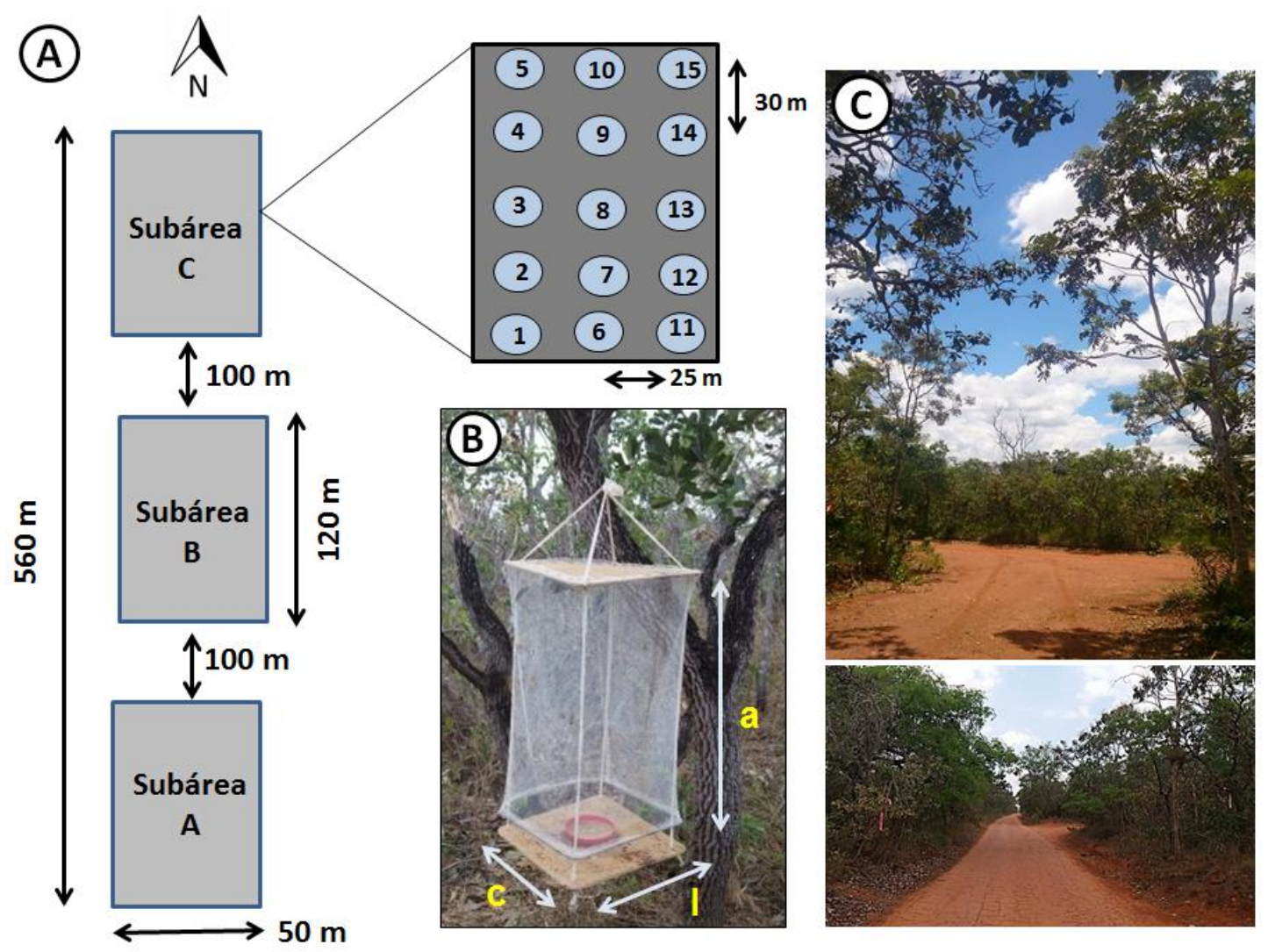

FIGURA 3. Desenho esquemático da área de estudo. A) Metragem das subáreas e disposição das armadilhas, B) Armadilha Van Someren-Rydon contendo ísca atrativa; C) Visão geral da vegetação de cerrado sensu stricto localizada nas áreas de estudo. Fotos: WS Rocha.

\subsection{Métodos de Campo}

As amostragens de borboletas foram realizadas semanalmente nos períodos de julout/2014 e jun-set/2015 com o uso de armadilhas tipo Van Someren-Rydon com as seguintes dimensões (25x25x45cm) (DeVries, 1987; Freitas et al., 2003) (Figura 3B). A isca utilizada nas armadilhas foi composta de banana fermentada em caldo de cana por 48 horas antes do uso (Uehara-Prado, 2003). Foram utilizadas em cada subárea amostral 15 armadilhas suspensas na vegetação a uma altura de 1-1,5 m acima do solo em locais sombreados e com espaçamento de 25-30m uma da outra, permanecendo armadas por aproximadamente $8 \mathrm{~h}$ diárias (de 8:00 às 16:00h), obtendo-se um esforço amostral total de 7.920 armadilhas/hora. Os indivíduos capturados foram marcados individualmente através de uma identificação numérica sequencial na face ventral das asas anteriores com canetas Sharpie de tinta indelével, não tóxica e não hidrossolúvel. No momento da captura foram anotados os 
seguintes dados: a espécie, o sexo, a idade aproximada (jovem, intermediário ou velho levando em consideração o grau de descamação das asas), o local da captura (subárea e número da armadilha) e a presença de marcas de bicadas de aves sobre as asas incluindo o número, o tipo de marcas encontradas (impressões ou "tears" = pedaços destacados da asa) e características como marcas simétricas ou assimétricas, que poderiam indicar se a borboleta foi atacada em repouso (com as asas fechadas) ou em voo (com as asas abertas, mostrando os padrões de cores miméticos). Apenas marcas com tamanho superior a $3 \mathrm{~mm}$ foram consideradas.

Dados sobre o tempo de residência de indivíduos na área de estudos, dispersão de indivíduos adultos e tamanhos populacionais foram obtidos através do método de capturamarcação-liberaçao-recaptura (CMLR). Todos os indivíduos capturados ou recapturados foram fotografados em vista dorsal e ventral e posteriormente liberados no mesmo local da captura.
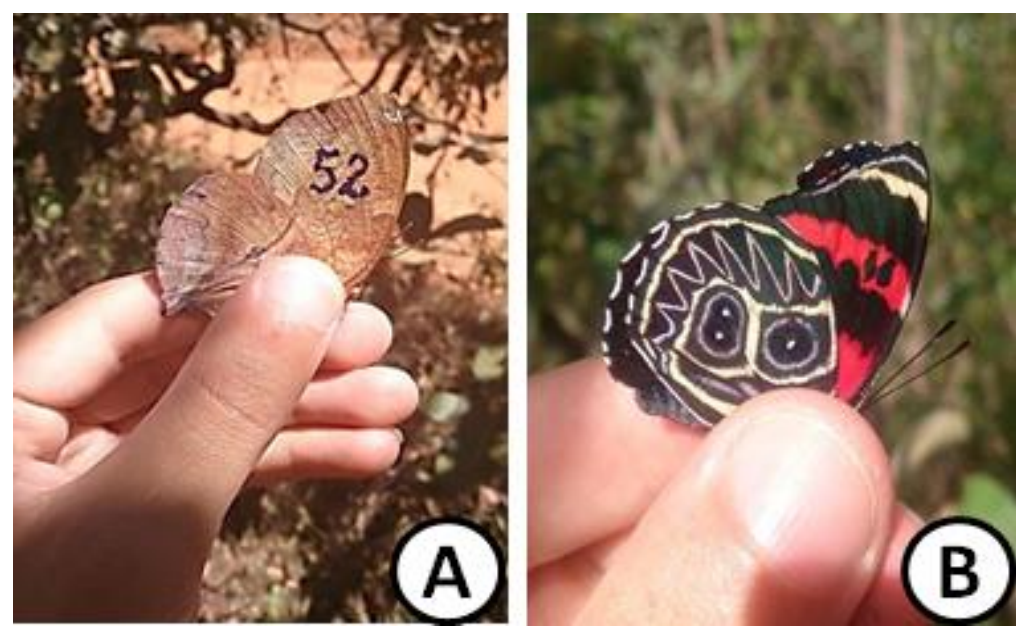

FIGURA 4. Marcação numérica na face ventral da asa anterior: A) S. galanthis; B) C. sorana. Foto: WS Rocha.

\subsection{Estimativas de Tamanhos Populacionais}

Estimativas de tamanhos populacionais foram realizadas através do método de Lincoln-Petersen com modificação de Bailey (1952) utilizado para populações fechadas (sem perdas ou ganhos durante intervalos amostrais) e baixo número de recapturas $(<20)$ (Francini, 2010). A fórmula geral da estimativa e de cálculos dos erros padrões é mostrada abaixo: 


$$
\begin{aligned}
& \widehat{\mathbf{N}}=\frac{M_{1}\left(C_{2}+1\right)}{\left(R_{1,2}+1\right)}=\text { estimativa do tamanho populacional } \\
& \mathbf{E P}(\widehat{\mathbf{N}})=\sqrt{\frac{\boldsymbol{M}_{1}^{2}\left(C_{2}+1\right)\left(C_{2-R_{2,1}}\right)}{\left(C_{2-R_{2,1}}\right)^{2}\left(R_{1,2}+2\right)}}=\text { erro padrão da estimativa do tamanho populacional }
\end{aligned}
$$

Onde:

$\widehat{\mathbf{N}}=$ estimativa do tamanho populacional

EP $(\widehat{\mathbf{N}})=$ erro padrão da estimativa do tamanho populacional

$\mathbf{M}_{1}=$ número de indivíduos marcados e soltos na primeira data

$\mathbf{C}_{2}=$ número de indivíduos capturados e examinados para marcas na segunda data

$\mathbf{R}_{\mathbf{1 , 2}}=$ número de indivíduos, entre os $\mathrm{C}_{2}$ indivíduos capturados na segunda data, marcados na data inicial.

\subsection{Testes de palatabilidade}

Grande parte das informações sobre predação de borboletas na natureza é baseada em ataques de aves insetívoras (Fryer, 1913; Pinheiro, 2011). Entretanto, outros predadores visualmente orientados como lagartos dos gêneros Anolis sp. (Polychrotidae), Ameiva sp. (Teiidae) e Tropidurus sp. (Tropiduridae) vêm sendo também utilizados em testes de palatabilidade por serem capazes de discriminar presas que possuem algum tipo defesa química com base no padrão de coloração de suas asas e no gosto presente em seus corpos (Boyden, 1976; Odendaal et al., 1987; Ehrlich \& Ehrlich, 1982). Outro importante predador usado em testes de palatabilidade com borboletas é a aranha Nephila clavipes (Linnaeus, 1767) (Nephilidade) (Vasconcellos-Neto \& Lewinsohn, 1984; Brown, 1984) que é eficiente em identificar defesas químicas de presas através de quimiorreceptores localizados nos pedipalpos (estruturas sensoriais). Neste estudo realizamos testes com Tropidurus itambere (Rodrigues, 1987) (Tropiduridae) e N. clavipes (Nephilidae) para investigar a palatabilidade de $S$. galanthis e C. sorana. 


\subsubsection{Experimentos com Nephila clavipes}

Entre o período de abril e junho de 2015 foram coletados com armadilhas atrativas 20 indivíduos de borboletas com diferentes faixas etárias (jovens, intermediários e velhos), sendo 10 indíviduos de $S$. galanthis e 10 de $C$. sorana (5 machos e 5 fêmeas de cada espécie) e oferecidos a diferentes fêmeas de Nephila clavipes (8 indivíduos) nas proximidades da área de estudo na Fazenda Água Limpa (UnB). As borboletas foram preparadas antes do ensaio através do corte parcial de uma das asas anteriores e posteriores para evitar sua fuga e danos à teia. Com o auxilio de uma pinça, as borboletas foram colocadas no centro da teia do lado oposto ao qual a aranha se encontrava. Em seguida, estas aranhas foram observadas e filmadas por um período de $30 \mathrm{~min}$.

As respostas dos predadores em relação à presa foram classificadas em 5 categorias adaptadas de acordo com Vasconcellos-Neto \& Lewinsohn (1984):

(1) Consumidas imediatamente: presa foi atacada, imobilizada (enrolada com fios de seda) e consumida;

(2) Consumidas tardiamente: presa foi atacada, imobilizada (enrolada com fios de seda) e guardada na dispensa (para posteiror consumo);

(3) Rejeitadas: presa foi atacada, imobilizada e rejeitada em seguida;

(4) Liberadas: presa foi liberada viva da teia pela aranha sem danos aparentes;

(5) Ignoradas: não houve contato físico entre predador - presa.

\subsubsection{Experimentos com Tropidurus itambere}

Foram coletados 12 individuos de $S$. galanthis $(\mathrm{n}=6)$ e $C$. sorana $(\mathrm{n}=6)$ com iguais proporções de machos e fêmeas e de diferentes faixas etárias durante o período de setembro a outubro de 2015. Os animais capturados através de armadilhas atrativas foram tratados (corte parcial de uma das asas anteriores e posteriores) e oferecidos aleatoriamente para 6 indivíduos de Tropidurus itambere (juvenis e adultos) encontrados em áreas abertas próximas da área de 
estudo na Fazenda Água Limpa - UnB. Após serem colocadas sobre o solo próximo às tocas dos lagartos, as borboletas foram observadas e filmadas por 30 minutos.

As seguintes categorias foram usadas para avaliar a reação do predador:

(1) Consumidos: presa foi atacada e consumida;

(2) Rejeitados: presa foi atacada e rejeitada em seguida (regurgitada);

(3) Ignorados: não houve contato físico entre predador - presa.

\subsection{Experimento sobre a vantagem do mimetismo em condições naturais}

A eficácia do mimetismo, independentemente do tipo de mimetismo encontrado entre estas espécies (Batesiano, Mülleriano ou mimetismo de escape) foi investigada neste estudo através da alteração da coloração original de $S$. galanthis de forma a torná-la não mimética na área de estudos. Para isto foram utilizadas as mesmas canetas usadas na marcação de indivíduos (canetas Sharpie). Dessa forma, dois grupos experimentais foram obtidos:

Grupo 1. 64 indivíduos (25 machos e 39 fêmeas) de S. galanthis com cores alteradas (grupo alterado) (Figura 5B).

Grupo 2. 65 indivíduos (26 machos e 39 fêmeas) de S. galanthis pintados (para efeito de padronização do método) de forma a não alterar o padrão de coloração original (grupo controle) (Figura 5A).

Hipóteses testadas em relação ao mimetismo e suas predições:

H1: A semelhança do padrão de coloração de asas de $S$. galanthis em relação a $C$. sorana protege a primeira de ataques de predadores.

H0: A semelhança do padrão de coloração de asas de $S$. galanthis em relação a $C$. sorana não protege a primeira de ataques de predadores. 
Predição 1: Indivíduos da população de S. galanthis com padrões de coloração alterados (G1) apresentam menor taxa de recaptura do que indivíduos com padrões de coloração inalterados $(\mathrm{G} 2)$.

Predição 2: Indivíduos da população de $S$. galanthis com padrões de coloração alterados (G1) apresentam menor tempo de residência do que indivíduos com padrões de coloração inalterados $(\mathrm{G} 2)$.

Predição 3: Indivíduos da população de S. galanthis com padrões de coloração alterados (G1) apresentam maior número de ataques de aves (marcas de bicadas) do que indivíduos com padrões de coloração inalterados (G2)
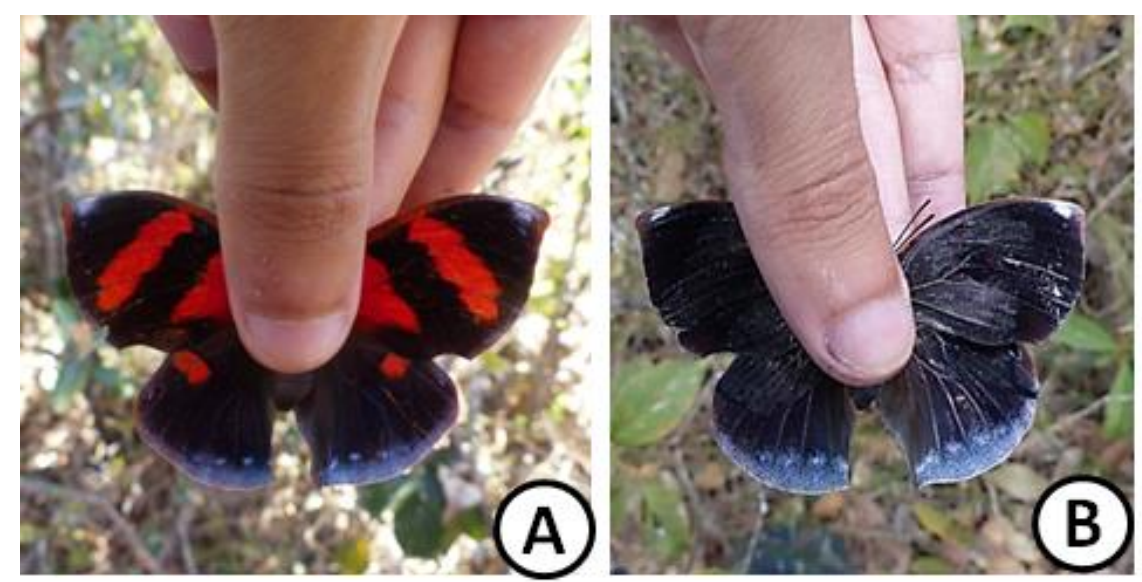

FIGURA 5. Alteração do padrão de coloração das asas de S. galanthis. A) Vista dorsal, não alterada (grupo controle); B), vista dorsal, alterada (grupo alterado). Fotos: WS Rocha.

\subsection{Testes Estatísticos}

Foram aplicados os testes estatísticos paramétricos (teste $t$; precedidos de teste Kolmogorov-Smirnov para normalidade bem como de um teste $\mathrm{F}$ para similaridade nas variâncias) para a comparação das médias de dispersão e marcas de bicada entre as espécies coletadas e testes não paramétricos (teste $X^{2}$, teste $U$ e $\mathrm{G}$ ) a fim de comparar diferenças entre S. galanthis e $C$. sorana quanto a razões sexuais, tempo de residência e frequência de recaptura. Os dados foram analisados com o auxílio do software estatístico Bioestat versão 5.3 . 


\section{RESULTADOS}

3.1 Números de animais marcados, recapturados, razões sexuais e tempo de residência

Foram marcados 190 adultos de $S$. galanthis (77 machos e 113 fêmeas) e 126 adultos de C. sorana (70 machos e 56 fêmeas), todos liberados após a marcação e/ou recaptura. O número total de indivíduos marcados, recapturados e as taxas de recapturas obtidas são apresentados na Tabela 1. Conforme podemos observar a maior taxa de recaptura obtida no estudo ocorreu com fêmeas de $C$. sorana $(25,0 \%)$ e a menor taxa com machos de $S$. galanthis $(16,8 \%)$

As razões sexuais encontradas para S. galanthis e C. sorana nos anos de 2014 e 2015 são apresentados na Tabela 2. Os resultados para S. galanthis em 2014 e no somatório dos dois anos investigados (dados agrupados) diferiram de uma razão de 1:1, enquanto para a espécie $C$. sorana não houve diferenças significativas.

O tempo médio de residência $(\overline{\mathrm{X}} \pm \mathrm{DP})$ de machos e fêmeas de $S$. galanthis e $C$. sorana bem como o tempo máximo de residência encontrado para cada sexo e espécie são mostrados na Figura 6. Em ambos os casos a residência máxima encontrada foi maior em fêmeas (respectivamente 50 e 46 dias) do que em machos (22 e 24 dias). Tendo em vista que estes dados não apresentaram uma distribuição normal as comparações entre sexos e espécies foram realizadas através de teste U (teste de Mann-Whitney). Nestas compações não foram encontradas diferenças significativas entre sexos ou espécies (Tabela 3). 
TABELA 1. Número de indivíduos marcados e taxas de recaptura durante o período de julho a outubro de 2014 e junho a setembro de 2015.

\begin{tabular}{|c|c|c|c|}
\hline Espécie / sexo & $\begin{array}{l}\text { Indivíduos } \\
\text { marcados }\end{array}$ & $\begin{array}{l}\text { Indivíduos } \\
\text { recapturados }\end{array}$ & Recaptura (\%) \\
\hline S. galanthis ठิ & 77 & 13 & 16.9 \\
\hline S. galanthis $\bigcirc$ & 113 & 21 & 18.6 \\
\hline Subtotal & 190 & 34 & 17.9 \\
\hline 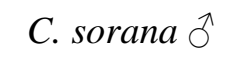 & 70 & 15 & 21.4 \\
\hline C. sorana & 56 & 14 & 25.0 \\
\hline Subtotal & 126 & 29 & 23.0 \\
\hline TOTAL & 316 & 63 & 19.9 \\
\hline
\end{tabular}

TABELA 2. Razões sexuais encontradas para $S$. galanthis e $C$. sorana na área de estudo nos anos de 2014 e 2015 . Valores de $X^{2}$ comparam os resultados obtidos com uma razão sexual de 1:1. Todos os testes com 1 g.l.

\begin{tabular}{ccccccc}
\hline Ano & Espécie & $0^{\lambda}$ & P & Proporção & $\boldsymbol{X}^{2}$ & $\boldsymbol{P}$ \\
\hline \multirow{2}{*}{2014} & S. galanthis & 51 & 78 & $0.65: 1$ & 5.651 & $0.017^{*}$ \\
& C. sorana & 53 & 37 & $1.43: 1$ & 2.844 & 0.091 \\
& & & & & & \\
\multirow{2}{*}{2015} & S. galanthis & 26 & 35 & $0.74: 1$ & 1.328 & 0.249 \\
& C. sorana & 17 & 19 & $0.89: 1$ & 0.111 & 0.738 \\
& & & & & & \\
\hline \multirow{2}{*}{$2014 / 2015$} & S. galanthis & 77 & 113 & $0.68: 1$ & 6.821 & $0.009^{*}$ \\
& C. sorana & 70 & 56 & $1.25: 1$ & 1.556 & 0.212 \\
\hline$(P<0,05)$ & & & & & &
\end{tabular}




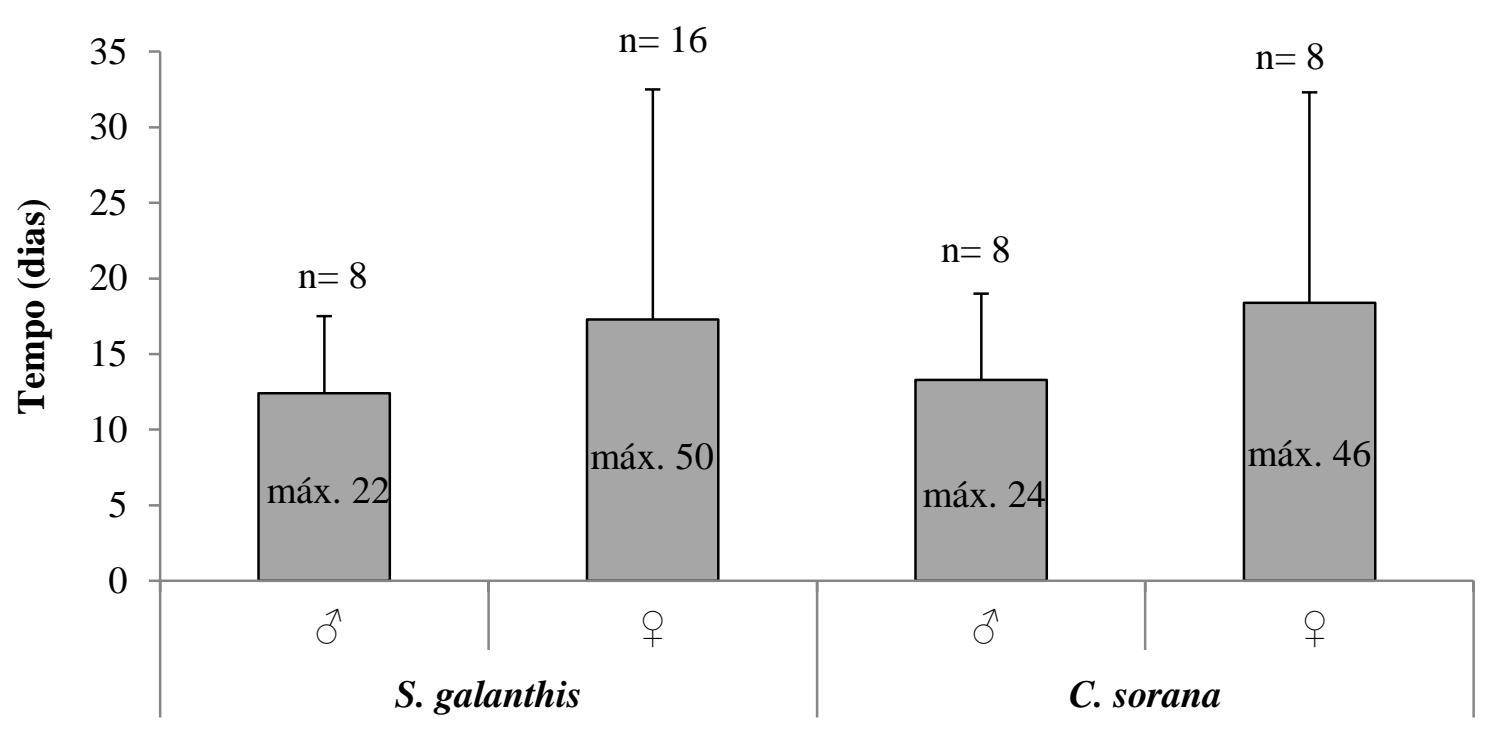

FIGURA 6. Tempo médio de residência de machos e fêmeas de $S$. galanthis e $C$. sorana durante o período de estudo. O número de indivíduos recapturados (n) e o tempo máximo de residência encontrado são também apresentados.

TABELA 3. Tempo de residência de machos e fêmeas de $S$. galanthis e $C$. sorana recapturados durante o estudo. O número de indivíduos (n) e testes de Mann-Whitney são também apresentados.

\begin{tabular}{|c|c|c|c|}
\hline Espécie / sexo & $\mathbf{n}$ & Teste U & $P$ \\
\hline S. galanthis ${ }^{\Uparrow}$ & 8 & \multirow{2}{*}{59.50} & \multirow{2}{*}{0.782} \\
\hline S. galanthis 우 & 16 & & \\
\hline 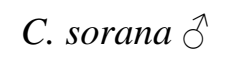 & 8 & \multirow{2}{*}{29.50} & \multirow{2}{*}{0.792} \\
\hline C. sorana + & 8 & & \\
\hline S. galanthis ठ & 8 & \multirow{2}{*}{30.00} & \multirow{2}{*}{0.833} \\
\hline C. sorana $\widehat{ठ}$ & 8 & & \\
\hline S. galanthis 우 & 16 & \multirow{2}{*}{51.50} & \multirow{2}{*}{0.444} \\
\hline C. sorana ${ }_{+}$ & 8 & & \\
\hline
\end{tabular}




\subsection{Tamanhos populacionais}

Durante os anos de 2014 e 2015 foram realizadas várias visitas à área de estudos em períodos distintos para verificar a presença de adultos de $S$. galanthis e $C$. sorana. Estas visitas mostraram que populações destas espécies começam a crescer apenas durante a estação seca quando atingem picos populacionais e declinam antes da chegada da estação chuvosa. Estimativas de tamanhos populacionais obtidas através do método de Lincoln-Bailey de machos e fêmeas (agrupados) de $S$. galanthis e $C$. sorana durante a estação seca são apresentadas na Figura 7. Apesar de pequenas variações nas estimativas obtidas podemos observar que os tamanhos populacionais destas espécies foram bastante semelhantes nos dois anos de estudo e apresentaram picos populacionais no mês de agosto.

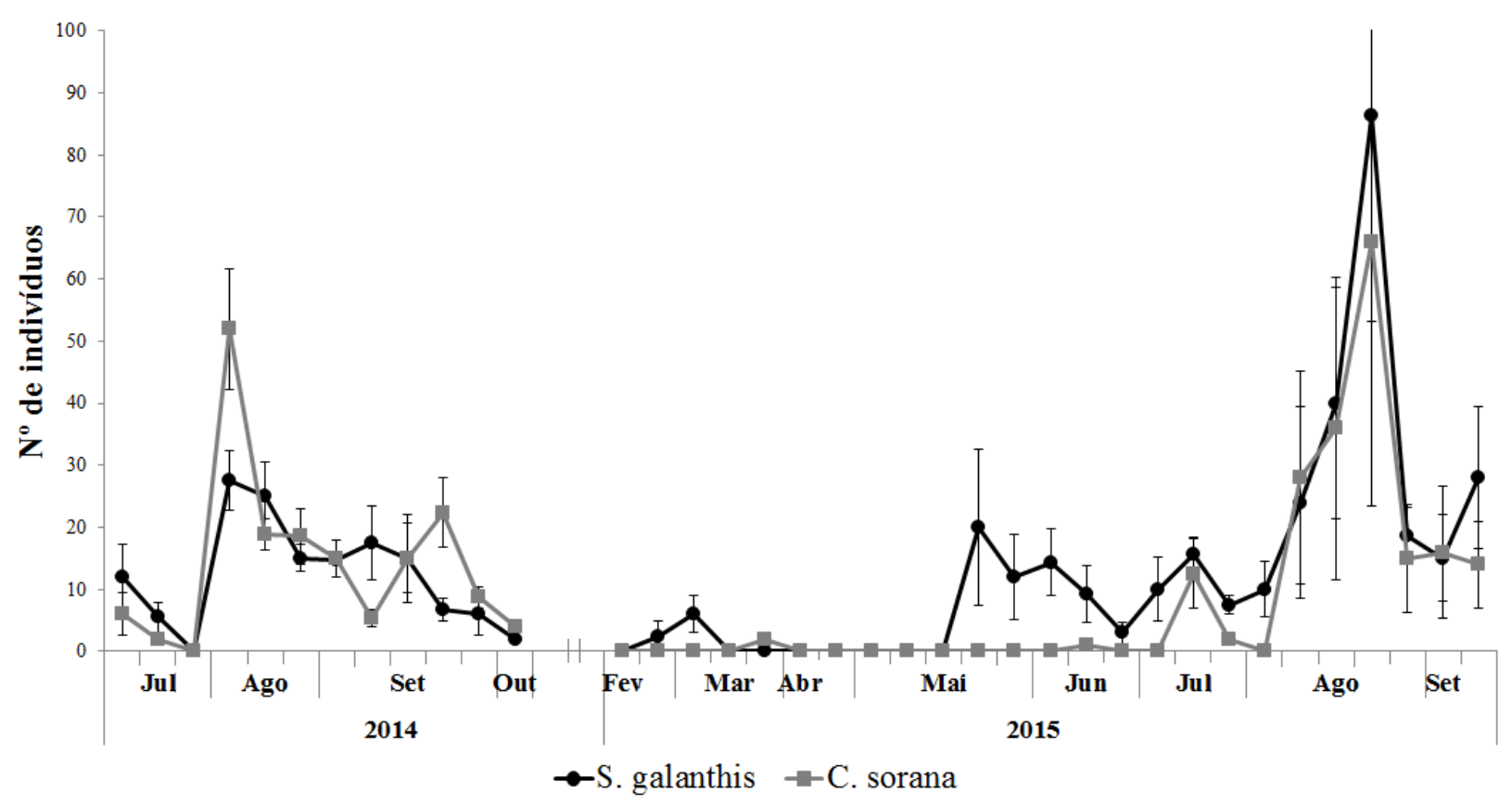

FIGURA 7. Estimativas de tamanhos populacionais de S. galanthis e C. sorana nos anos de 2014 e 2015 com seus respectivos erros padrões. 
As médias das distâncias lineares percorridas entre sucessivas capturas de machos e fêmeas de $S$. galanthis e $C$. sorana nas áreas de estudo são apresentadas na Figura 8. As maiores distâncias foram encontradas em fêmeas $(502 \mathrm{~m}$ em $S$. galanthis e $500 \mathrm{~m}$ em $C$. sorana). Comparações entre sexos e espécies realizadas através de teste $t$ não mostraram diferenças significativas entre sexos e nem entre as espécies investigadas (Tabela 4).

Comparações envolvendo a frequência de recapturas na mesma subárea ou em subáreas diferentes também não mostraram diferenças significativas entre sexos nas duas espécies investigadas, nem nas comparações envolvendo machos das duas espécies. Entretanto, foi encontrada uma diferença significativa na comparação entre fêmeas das duas espécies, sendo que fêmeas de S. galanthis foram mais recapturadas em subáreas diferentes da marcação original e $C$. sorana mais recapturada na mesma subárea da marcação, indicando que há maior residência em fêmeas de C. sorana do que em fêmeas de S. galanthis (Figura 9, Tabela 5). 


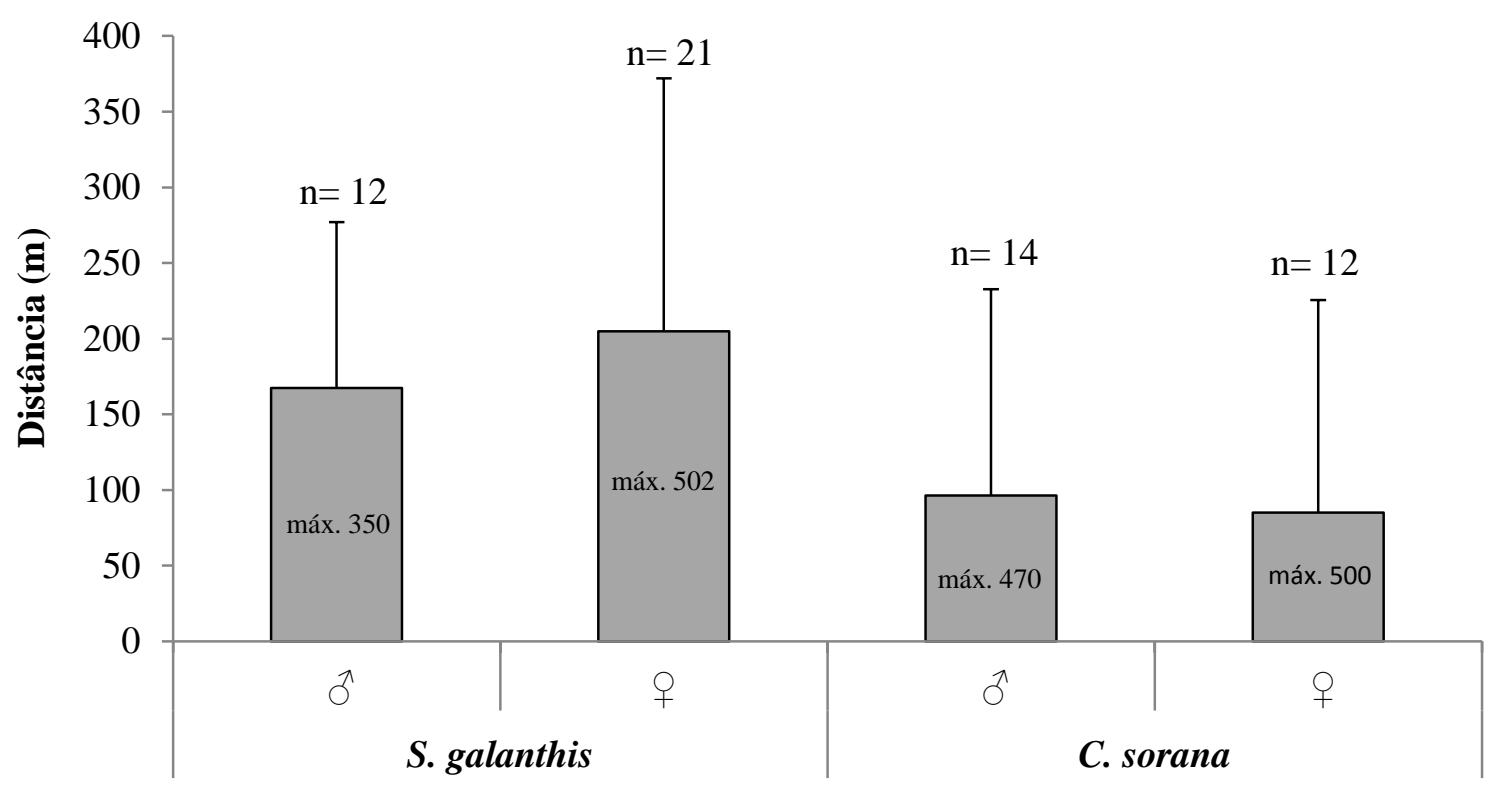

FIGURA 8. Média das distâncias lineares percorridas $(\overline{\mathbf{X}}+\mathrm{DP})$ entre sucessivas capturas de indivíduos de $S$. galanthis e $C$. sorana na área de estudo. O número de deslocamentos (n) e as distâncias máximas percorridas (em metros) são também apresentados.

TABELA 4. Comparações das distâncias lineares percorridas por indivíduos de $S$. galanthis e $C$. sorana entre sucessivas recapturas. O número de indivíduos (n) e os valores do teste $t$ são também apresentados.

\begin{tabular}{|c|c|c|c|c|}
\hline Espécie / Sexo & $\mathbf{n}$ & Teste $t$ & $P$ & g.l. \\
\hline $\begin{array}{l}\text { S. galanthis }{ }^{\lambda} \\
\text { S. galanthis } \text { 우 }\end{array}$ & $\begin{array}{l}12 \\
21\end{array}$ & 0.648 & 0.522 & 25 \\
\hline $\begin{array}{l}\text { C. sorana }{ }^{\lambda} \\
\text { C. sorana } \stackrel{+}{\phi}\end{array}$ & $\begin{array}{l}14 \\
12\end{array}$ & 0.188 & 0.852 & 20 \\
\hline $\begin{array}{l}\text { S. galanthis }{ }^{\lambda} \\
\text { C. sorana }{ }^{\lambda}\end{array}$ & $\begin{array}{l}12 \\
14\end{array}$ & 1.351 & 0.191 & 20 \\
\hline $\begin{array}{l}\text { S. galanthis }+ \text { } \\
\text { C. sorana }{ }^{\circ}\end{array}$ & $\begin{array}{l}21 \\
12\end{array}$ & 1.945 & 0.062 & 25 \\
\hline
\end{tabular}




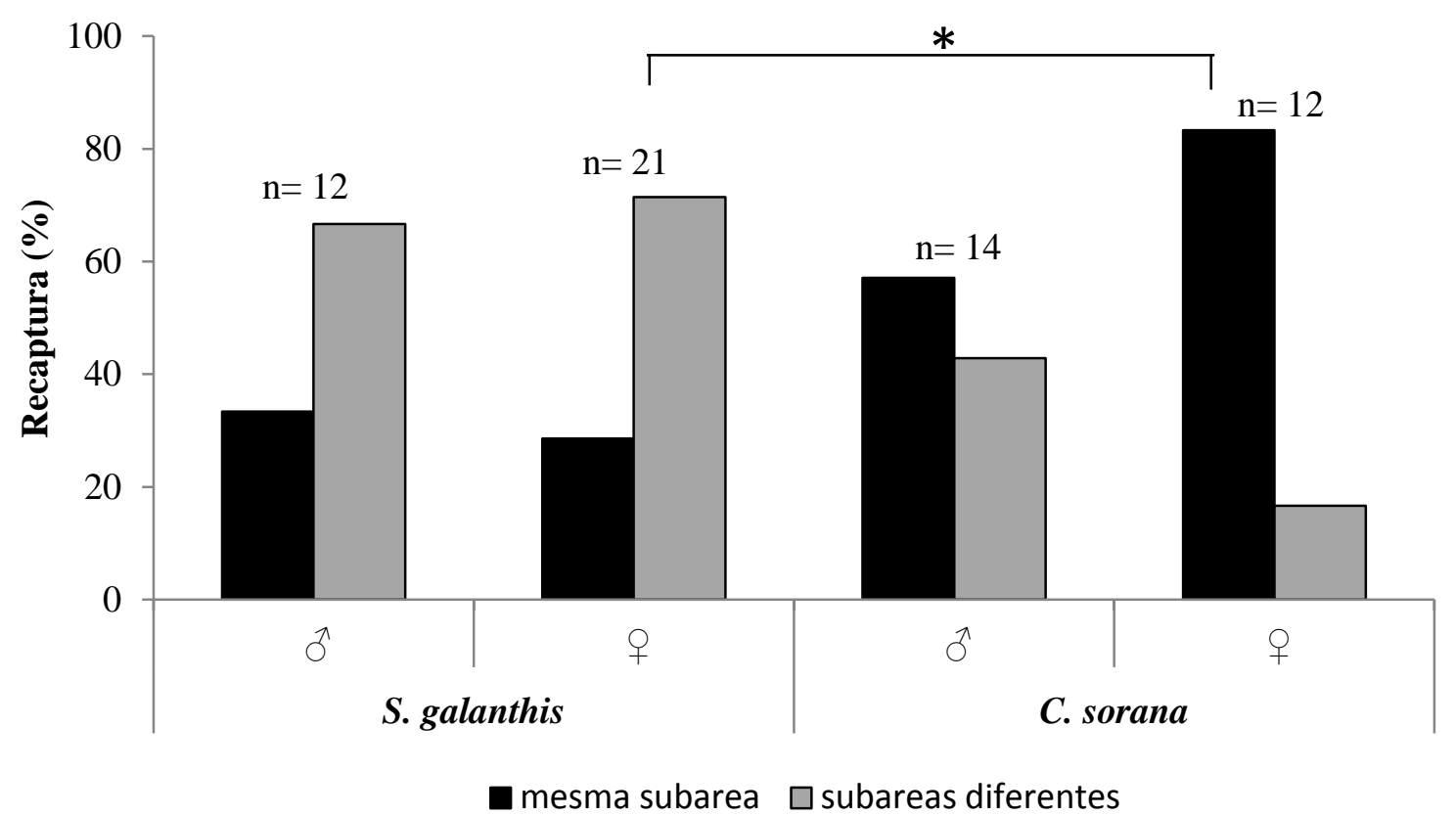

FIGURA 9. Frequência de recapturas de indivíduos na mesma subárea da captura e em diferentes subáreas de estudo. O número de deslocamentos (n) obtidos para cada espécie e sexo também são apresentados. $\mathrm{O}$ asterisco indica resultado com significância estatatística $(P<0,05)$.

TABELA 5. Frequência de recapturas de indivíduos na mesma subárea da captura original e em diferentes subáreas de estudo. O número de deslocamentos (n) obtidos para cada espécie e sexo, os valores do teste $\mathrm{G}$ (Williams) são apresentados.

\begin{tabular}{|c|c|c|c|}
\hline Espécie/ sexo & $\mathbf{n}$ & $\begin{array}{c}\text { Teste G } \\
\text { (Williams) }\end{array}$ & $P$ \\
\hline 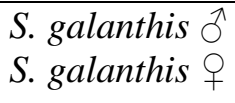 & $\begin{array}{l}12 \\
21\end{array}$ & 0.076 & 0.782 \\
\hline $\begin{array}{l}\text { C. sorana } \hat{\circ} \\
\text { C. sorana } \stackrel{+}{+}\end{array}$ & $\begin{array}{l}14 \\
12\end{array}$ & 2.017 & 0.155 \\
\hline $\begin{array}{l}\text { S. galanthis } \widehat{0}^{\lambda} \\
\text { C. sorana }{ }^{\lambda}\end{array}$ & $\begin{array}{l}12 \\
14\end{array}$ & 1.409 & 0.235 \\
\hline $\begin{array}{l}\text { S. galanthis }{ }^{+} \\
\text {C. sorana }{ }^{\circ}\end{array}$ & $\begin{array}{l}21 \\
12 \\
\end{array}$ & 9.307 & $0.002^{*}$ \\
\hline
\end{tabular}

$*(P<0,05)$. 
No total foram encontradas 429 marcas de bicadas em adultos de S. galanthis (196 em machos e 233 em fêmeas) e 132 marcas em C. sorana (69 em machos e 63 em fêmeas). Todas as marcas encontradas foram do tipo "tear" (ver métodos; Figura 10).
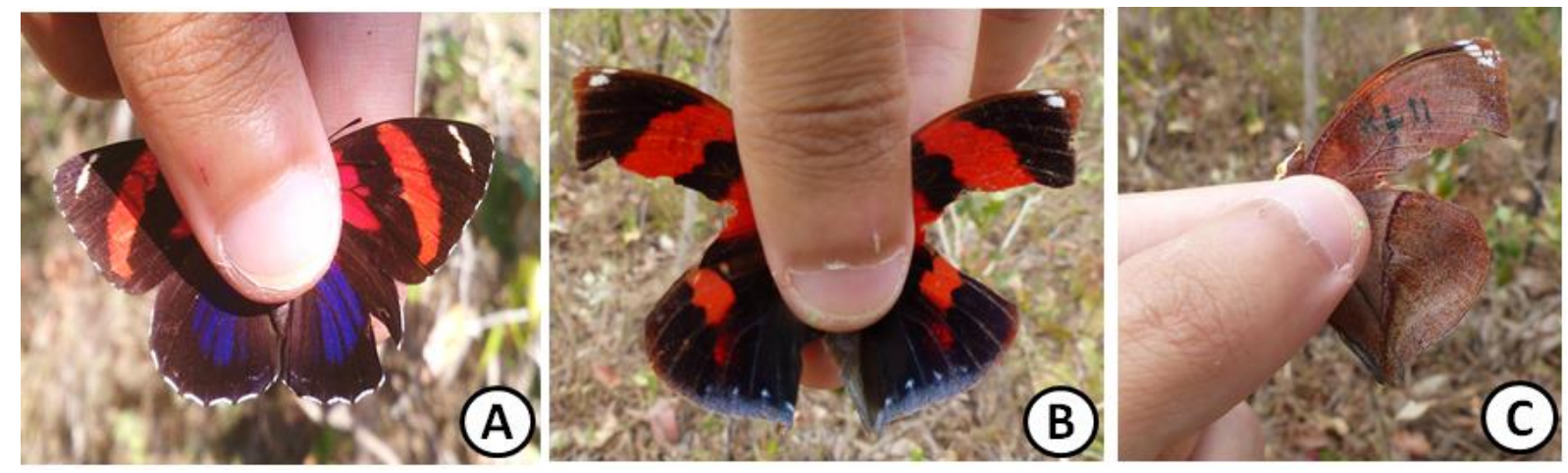

FIGURA 10. Marcas do tipo "tears". A) marca assimétrica em C. sorana, vista dorsal; B) marca simétrica em S. galanthis, vista dorsal e C) S. galanthis, vista ventral. Fotos: WS Rocha.

A maior proporção de indivíduos com marcas de bicadas (independente do número de marcas individuais) foi encontrada em $S$. galanthis (58,4\% em machos e 59,3\% em fêmeas) enquanto que em C. sorana esta proporção foi menor $(40,0 \%$ em machos e $50,0 \%$ em fêmeas). Comparações realizadas através de teste de $X^{2}$ (Tabelas de Contingência) envolvendo estes valores não mostraram diferenças significativas entre sexos destas espécies e nem entre fêmeas das duas espécies investigadas, mas mostraram diferenças significativas entre machos de S. galanthis e C. sorana (Tabela 6). 
TABELA 6. Número e porcentagem de machos e fêmeas de $S$. galanthis e $C$. sorana apresentando ou não marcas de bicadas e as comparações realizadas com o teste de $X^{2}$ (todos os testes com 1 g.l.).

\begin{tabular}{|c|c|c|c|c|}
\hline Espécies / Sexo & sem marcas & com marcas (\%) & $X^{2}$ & $\boldsymbol{P}$ \\
\hline $\begin{array}{l}\text { S. galanthis } \widehat{\widehat{O}} \\
\text { S. galanthis } \bigcirc\end{array}$ & $\begin{array}{l}32(41,6) \\
46(40,7)\end{array}$ & $\begin{array}{l}45(58,4) \\
67(59,3)\end{array}$ & 0.014 & 0.906 \\
\hline $\begin{array}{l}\text { C. sorana } 0 \\
\text { C. sorana } \bigcirc\end{array}$ & $\begin{array}{l}42(60,0) \\
28(50,0)\end{array}$ & $\begin{array}{l}28(40,0) \\
28(50,0)\end{array}$ & 1.260 & 0.261 \\
\hline 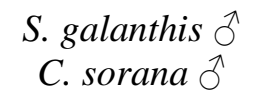 & $\begin{array}{l}32(41,6) \\
42(60,0)\end{array}$ & $\begin{array}{l}45(58,4) \\
28(40,0)\end{array}$ & 4.988 & $0.025^{*}$ \\
\hline $\begin{array}{c}\text { S. galanthis }+9 \\
\text { C. sorana } 9\end{array}$ & $\begin{array}{l}46(40,7) \\
28(50,0)\end{array}$ & $\begin{array}{l}67(59,3) \\
28(50,0)\end{array}$ & 1.313 & 0.251 \\
\hline
\end{tabular}

As proporções de marcas simétricas e assimétricas encontradas em machos e fêmeas de $S$. galanthis e C. sorana são apresentadas na Figura 11. Em todos os casos a proporção de marcas assimétricas, que indicam que as borboletas foram atacadas em vôo (ou com as asas abertas), foi maior do que a proporção de marcas simétricas, que indicam que as borboletas foram atacadas em repouso (com as asas fechadas). Comparações envolvendo estes dois tipos de marcas não mostraram diferenças significativas entre sexos destas espécies, mas mostraram diferenças significativas nas comparações entre espécies (Tabela 7). Estas comparações mostram que $S$. galanthis é igualmente atacada em vôo ou em repouso, enquanto C. sorana é proporcionalmente mais atacada em vôo do que em repouso.

Além das características acima também foi observado que o número médio de marcas encontradas é diretamente proporcional à idade das borboletas, ou seja, é menor em indivíduos jovens e maior em indivíduos velhos, com indivíduos com idades intermediárias apresentando valores intermediários entre as demais classes etárias (ver Figura 12 para marcas simétricas e Figura 13 para marcas assimétricas). 


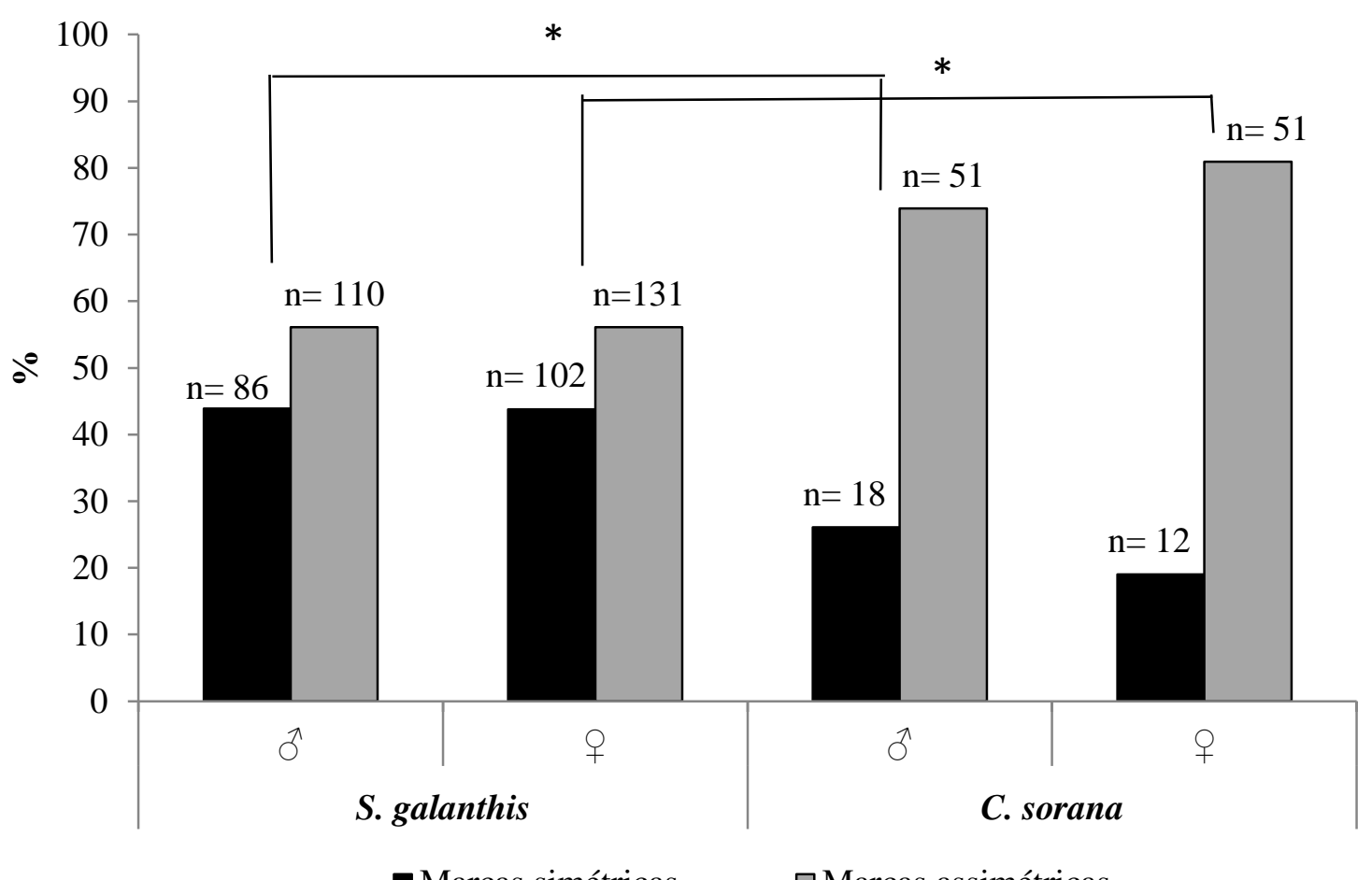

FIGURA 11. Proporção de marcas simétricas e assimétricas encontradas em machos e fêmeas de $S$. galanthis e $C$. sorana. $\mathrm{O}$ número de marcas (n) encontrado é apresentado. $\mathrm{O}$ asterisco indica resultado com significância estatística $(P<0,05)$.

TABELA 7. Número de marcas simétricas e assimétricas encontradas em machos e fêmeas de $S$. galanthis e $C$. sorana e as comparações realizadas através de teste $X^{2}$.

\begin{tabular}{|c|c|c|c|c|c|}
\hline Espécies / Sexo & $\begin{array}{l}\mathbf{N}^{\text {o }} \text { total de } \\
\text { marcas }\end{array}$ & $\begin{array}{c}\text { Marcas } \\
\text { simétricas } \\
(\%)\end{array}$ & $\begin{array}{c}\text { Marcas } \\
\text { assimétricas } \\
(\%)\end{array}$ & $X^{2}$ & $P$ \\
\hline S. galanthis ô & 196 & $86(43,9)$ & $110(56,1)$ & \multirow{2}{*}{0.006} & \multirow{2}{*}{0.938} \\
\hline S. galanthis $q$ & 233 & $102(43,8)$ & $131(56,1)$ & & \\
\hline C. sorana ${ }^{\lambda}$ & 69 & $18(26,1)$ & $51(73,9)$ & \multirow{2}{*}{0.572} & \multirow{2}{*}{0.449} \\
\hline C. sorana ㅇ & 46 & $12(19,0)$ & $51(80,9)$ & & \\
\hline S. galanthis $\widehat{0}$ & 196 & $86(43,9)$ & $110(56,1)$ & \multirow{2}{*}{6.049} & \multirow{2}{*}{0.013} \\
\hline C. sorana $\partial^{\lambda}$ & 69 & $18(26,1)$ & $51(73,9)$ & & \\
\hline S. galanthis $q$ & 233 & $102(43,8)$ & $102(43,8)$ & \multirow{2}{*}{11.784} & \multirow{2}{*}{0.001} \\
\hline C. sorana 9 & 46 & $12(19,0)$ & $51(80,9)$ & & \\
\hline
\end{tabular}




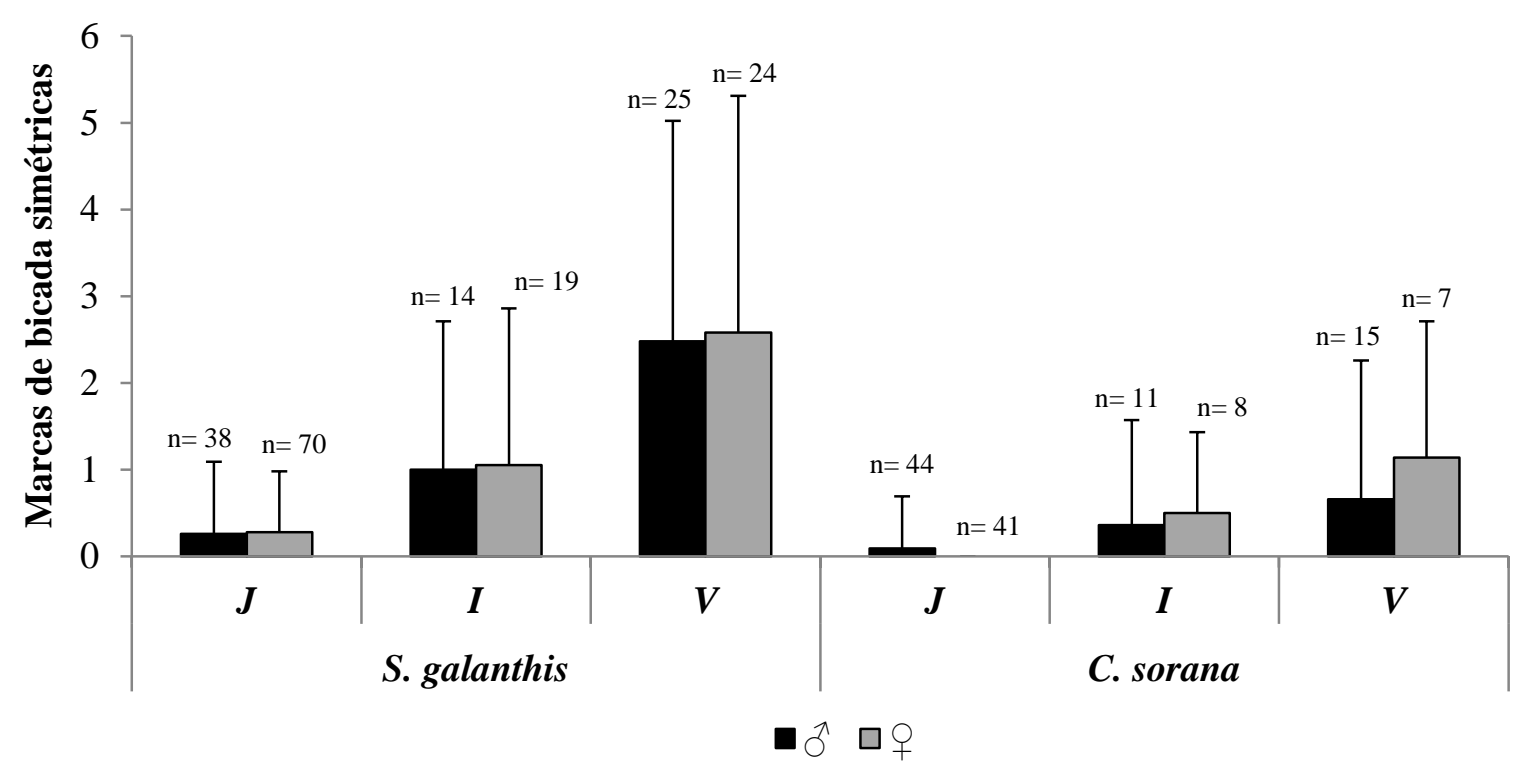

FIGURA 12. Média de marcas de bicadas simétricas por sexo e idade ( $\mathrm{J}=$ jovem, $\mathrm{I}=$ intermediário e $\mathrm{V}=$ velho) em $S$. galanthis e $C$. sorana. O número de indivíduos em cada classe etária (n) também é apresentado.

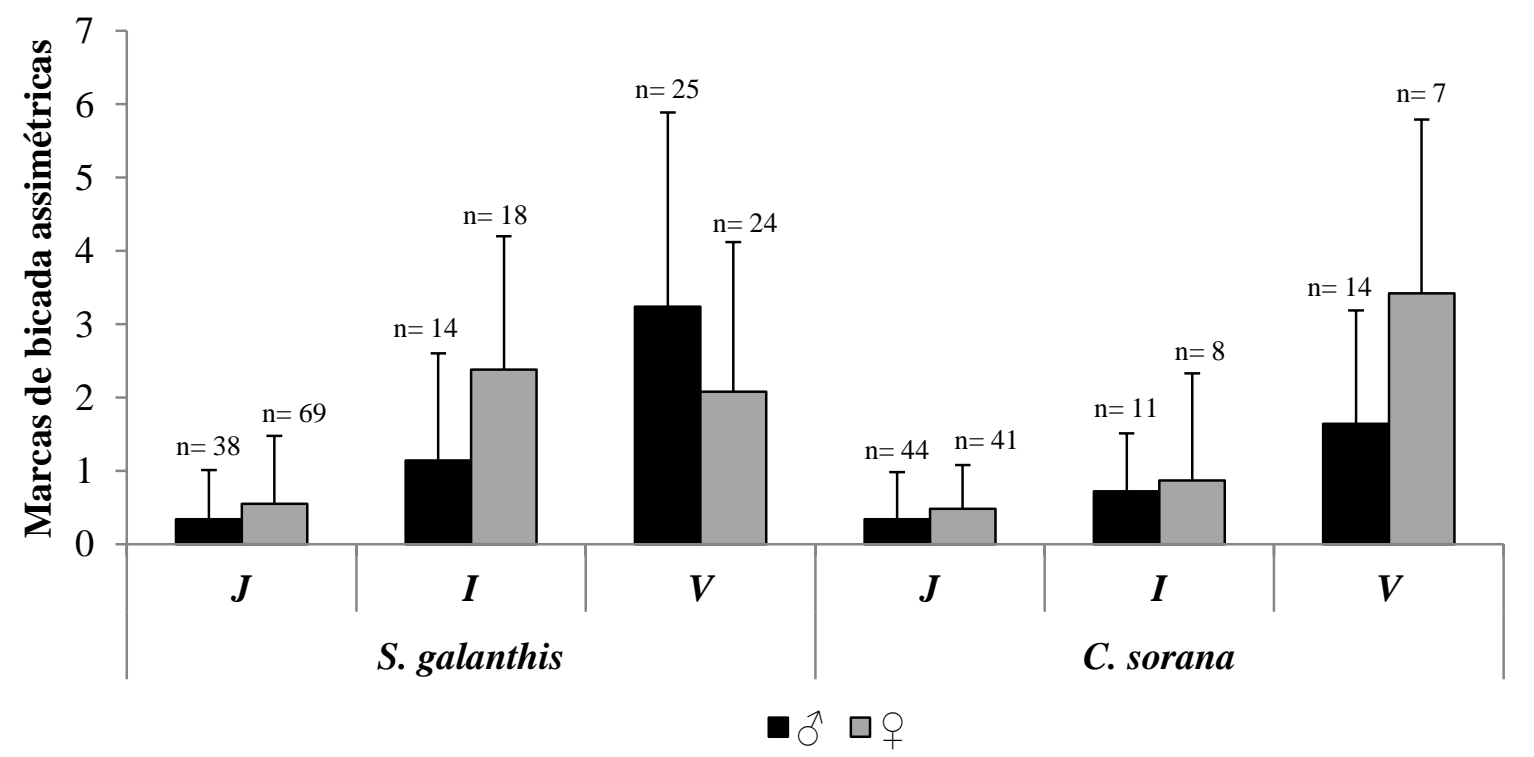

FIGURA 13. Média de marcas de bicadas assimétricas por sexo e idade ( $\mathrm{J}=$ jovem, $\mathrm{I}=$ intermediário e $\mathrm{V}=$ velho) em $S$. galanthis e $C$. sorana. O número de indivíduos em cada faixa etária (n) também é apresentado. 
Considerando-se apenas as marcas assimétricas, obviamente mais relevantes para a compreensão do mimetismo entre $S$. galanthis e $C$. sorana do que as marcas simétricas, várias comparações realizadas entre indivíduos do mesmo sexo e idade entre estas espécies não mostraram diferenças significativas entre si (exceto no caso de machos velhos e de fêmeas intermediárias; Tabela 8). Estas comparações indicam que $S$. galanthis e $C$. sorana apresentam habilidades semelhantes para escapar de ataques de predadores.

TABELA 8. Comparações da média de marcas de bicadas assimétricas entre indivíduos do mesmo sexo e idade (J= jovem, $\mathrm{I}=$ intermediário e $\mathrm{V}=$ velho) de $S$. galanthis e $C$. sorana. $\mathrm{O}$ número de indivíduos em cada faixa etária (n) e os valores do teste $t$ são também apresentados.

\begin{tabular}{|c|c|c|c|}
\hline $\begin{array}{c}\text { S. galanthis } \mathrm{x} C \text {. sorana } \\
\text { Sexo/Idade }\end{array}$ & Teste $t$ & $P$ & g.l. \\
\hline$\hat{\jmath} \mathbf{J}(\mathrm{n}=38) \times \hat{O} \mathbf{J}(\mathrm{n}=44)$ & 0.008 & 0.993 & 80.00 \\
\hline$\widehat{\partial} \mathrm{I}(\mathrm{n}=14) \times \curvearrowright \mathrm{I}(\mathrm{n}=11)$ & 0.849 & 0.404 & 23.00 \\
\hline 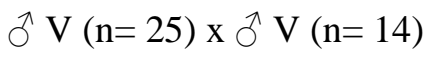 & 2.374 & $0.023^{*}$ & 36.88 \\
\hline$q \mathbf{J}(\mathrm{n}=69) \times(+\mathbf{J}(\mathrm{n}=41)$ & 0.431 & 0.667 & 107.34 \\
\hline$q \mathrm{I}(\mathrm{n}=18) \mathrm{x}$ ㅇ $\mathrm{I}(\mathrm{n}=8)$ & 2.069 & $0.049 *$ & 24.00 \\
\hline 아 $\mathrm{V}(\mathrm{n}=24) \mathrm{x}$ ㅇ $\mathrm{V}(\mathrm{n}=7)$ & 1.481 & 0.149 & 29.00 \\
\hline
\end{tabular}




\subsection{Testes de palatabilidade}

Experimentos de palatabilidade com Nephila clavipes (Figura 14A) mostraram que todos os indivíduos de $S$. galanthis $(\mathrm{n}=10)$ e $C$. sorana $(\mathrm{n}=10)$ colocados nas teias foram imediatamente atacados, imobilizados (enrolados com fios de seda) e posteriormente consumidos (aparentemente com líquidos e partes moles sendo sugados) pelas aranhas até o período final de observação (30 min) (Figura 14B e C). Curiosamente, a partir do momento em que foram colocados na teia, e também durante o ataque e imobolização pelas aranhas, os indivíduos de $S$. galanthis permaneceram imóveis (comportamento conhecido como tanatose), enquanto que indivíduos de $C$. sorana mostraram-se bastante agitados durante todo este processo, debatendo-se várias vezes contra a teia.
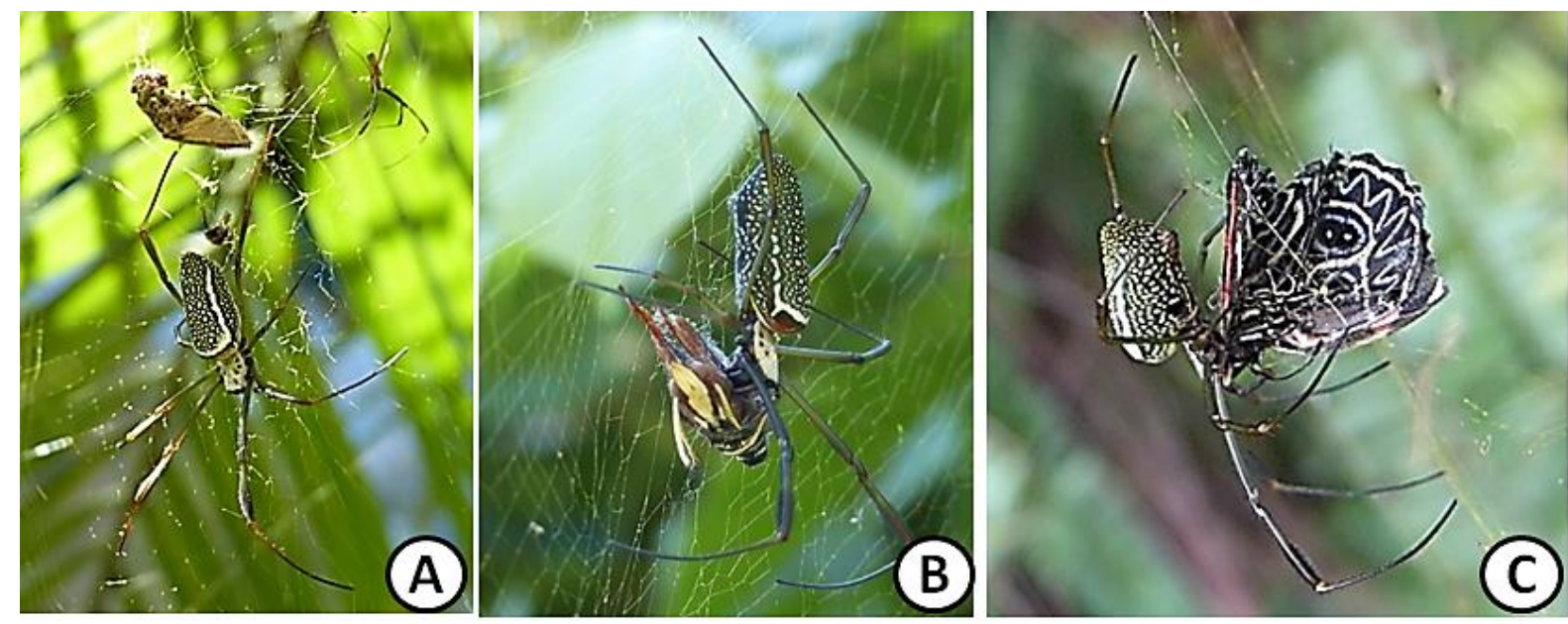

FIGURA 14. Teste de palatabilidade com Nephila clavipes. A) Fêmea de Nephila clavipes (maior) ao lado de um macho (menor); B) N. clavipes predando S. galanthis; C) N. clavipes predando C. sorana. Fotos: WS Rocha.

De forma semelhante ao que aconteceu com os experimentos com Nephila clavipes, poucos minutos após os indivíduos $S$ galanthis $(\mathrm{n}=6)$ e $C$. sorana $(\mathrm{n}=6)$ serem colocados sobre o solo e próximo às tocas de Tropidurus itambere (Figura 15A), todas as borboletas foram atacadas e imediatamente consumidas pelos lagartos (Figura 15B e C). Além disto, não foram observados quaisquer comportamentos aversivos nos lagartos que pudessem indicar a presença de odores ou gostos desagradáveis ou repugnantes antes ou após o consumo das borboletas. 
Estes resultados sugerem que $S$. galanthis e $C$. sorana não utilizam defesas químicas contra predadores. Entretanto, notou-se uma dificuldade maior na deglutição de indivíduos de S. galanthis do que indivíduos de C. sorana, talvez devido ao fato da primeira possuir asas maiores e aparentemente mais resistentes do que a última.

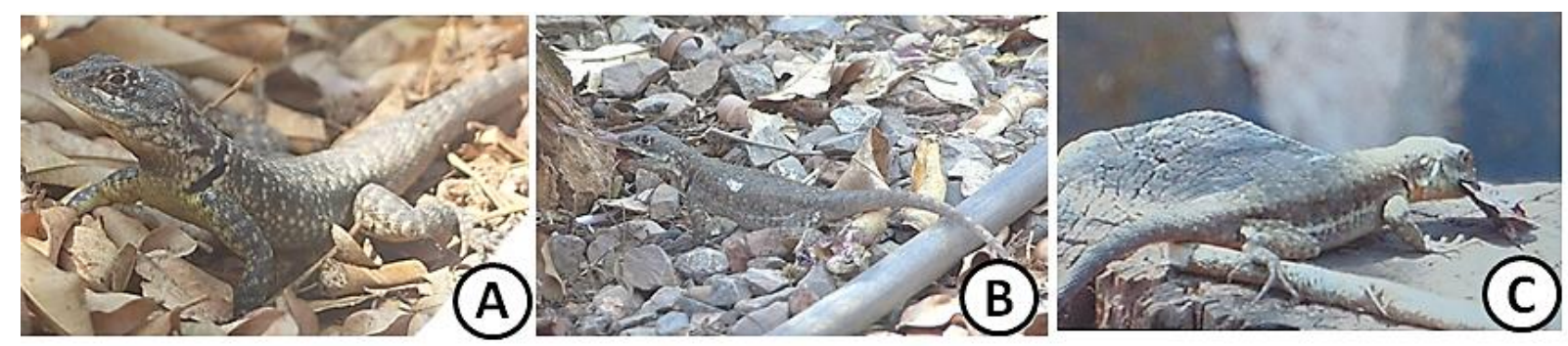

FIGURA 15. Teste de palatabilidade com Tropidurus itambere. A) Indivíduo de T. itambere; B) $T$. itambere predando C. sorana; C) T. itambere predando S. galanthis. Fotos: WS Rocha. 


\subsection{Experimento sobre a vantagem do mimetismo em condições naturais}

Neste experimento procurou-se testar a vantagem do mimetismo na natureza ao modificar o padrão de coloração de uma das espécies investigadas ( $S$. galanthis) de modo a torná-lo não mimético na área de estudos (as hipóteses e as predições testadas são apresentadas no quadro abaixo).

\section{Hipóteses e predições}

H1: A semelhança do padrão de coloração de asas de $S$. galanthis em relação a $C$. sorana protege a primeira de ataques de predadores.

H0: A semelhança do padrão de coloração de asas de $S$. galanthis em relação a C. sorana não protege a primeira de ataques de predadores.

Predição 1: Indivíduos da população de $S$. galanthis com padrões de coloração alterados (G1) apresentam menor taxa de recaptura do que indivíduos com padrões de coloração inalterados (G2).

Predição 2: Indivíduos da população de S. galanthis com padrões de coloração alterados (G1) apresentam menor tempo de residência do que indivíduos com padrões de coloração inalterados $(\mathrm{G} 2)$.

Predição 3: Indivíduos da população de S. galanthis com padrões de coloração alterados (G1) apresentam maior número de ataques de aves (marcas de bicadas) do que indivíduos com padrões de coloração inalterados (G2).

Os resultados obtidos, entretanto, foram todos contrários às predições formuladas. Em primeiro lugar, as taxas de recapturas de indivíduos com cores alteradas foram superiores às taxas de recapturas de indivíduos com coloração não alterada (Predição 1, Tabela 9).

Em segundo lugar, o tempo médio de residência de indivíduos com cores alteradas (apesar de superior nas fêmeas) não diferiu significativamente do tempo médio de residência de indivíduos com coloração não alterada $\left(\mathrm{n}_{1}=4 ; \mathrm{n}_{2}=3 ; t=1.268, P=0.260\right.$ na comparação entre machos; $\mathrm{n}_{1}=9 ; \mathrm{n}_{2}=5 ; t=1.477 ; P=0.165$ na comparação entre fêmeas; Predição 2; Tabela 10).

Finalmente, a média de marcas de bicadas encontradas em indivíduos com padrões de cores não alterados foi maior do que a média encontrada em indivíduos com cores alteradas (Predição 3; Figura 16). 
Assim, nenhuma das predições testadas corroborou a hipótese formulada. Estes resultados inesperados foram atribuídos ao baixo número de recapturas de indivíduos encontrados nos dois grupos experimentais (ver discussão).

TABELA 9. Número de indivíduos com padrões de coloração alterados e não alterados com suas respectivas taxas de recapturas.

\begin{tabular}{|c|c|c|c|c|}
\hline Espécie / sexo & Não alterados & Recapturas & Alterados & Recapturas \\
\hline $\begin{array}{l}\text { S. galanthis } 0 \\
\text { S. galanthis } \bigcirc\end{array}$ & $\begin{array}{l}26 \\
39\end{array}$ & $\begin{array}{l}3(11,53 \%) \\
5(12,82 \%)\end{array}$ & $\begin{array}{l}25 \\
39\end{array}$ & $\begin{array}{l}4(16,00 \%) \\
9(23,07 \%)\end{array}$ \\
\hline Total & 65 & $8(12,30 \%)$ & 64 & $13(20,31 \%)$ \\
\hline
\end{tabular}

TABELA 10. Tempo médio de residência $(\bar{X} \pm$ DP) de indivíduos com padrões de coloração alterados e não alterados (n).

\begin{tabular}{|c|c|c|c|c|}
\hline Espécie / sexo & Não alterados & $\overline{\mathbf{X}} \pm \mathrm{DP}$ & Alterados & $\overline{\mathbf{X}} \pm \mathrm{DP}$ \\
\hline $\begin{array}{l}\text { S. galanthis }{ }^{\pi} \\
\text { S. galanthis }\end{array}$ & $\begin{array}{l}3 \\
5\end{array}$ & $\begin{array}{c}5,33 \pm 3,79 \\
22,40 \pm 19,37\end{array}$ & $\begin{array}{l}4 \\
9\end{array}$ & $\begin{array}{c}12,00 \pm 8,33 \\
10,00 \pm 12,32\end{array}$ \\
\hline Total & 8 & $16,00 \pm 17,22$ & 13 & $10,62 \pm 10,93$ \\
\hline
\end{tabular}

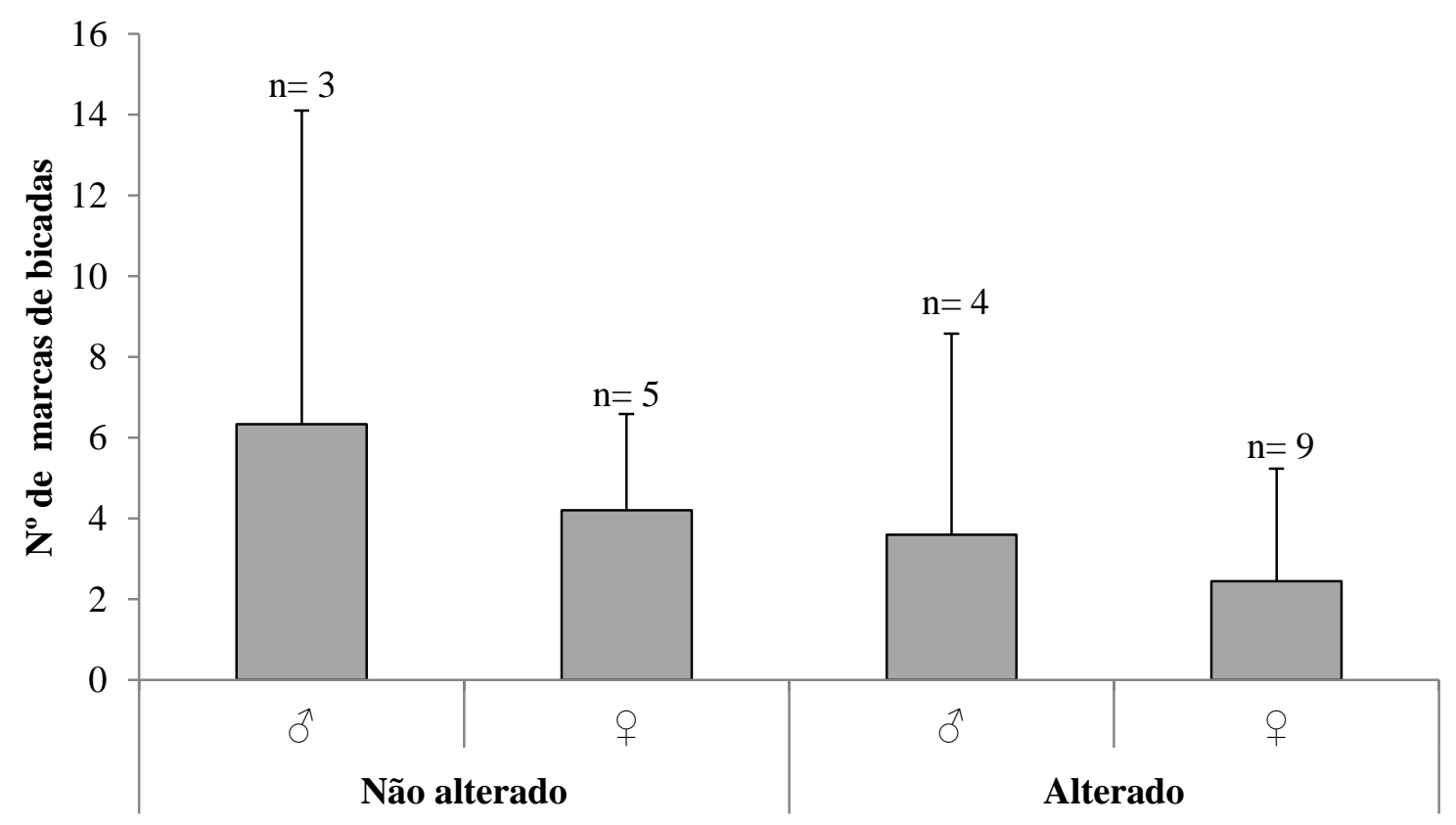

FIGURA 16. Número médio de marcas de bicadas encontradas em indivíduos de S. galanthis com padrões de cores não alterados e alterados. O número de indivíduos recapturados (n) e os desvios padrões são também apresentados. 


\section{DISCUSSÃO}

Vários resultados obtidos neste estudo indicam que $S$. galanthis e $C$. sorana não constituem um caso clássico de mimetismo Batesiano ou Mülleriano. Em primeiro lugar, não foram encontradas quaisquer evidências de que estas espécies apresentem compostos químicos defensivos que pudessem ser utilizados contra predadores, seja no caso dos experimentos com a aranha $N$. clavipes como também no caso do lagarto $T$. itambere que atacaram e consumiram todas as borboletas oferecidas aos mesmos nos testes de palatabilidade realizados. A presença de compostos químicos defensivos era esperada pelo menos nos indivíduos de $C$. sorana após os experimentos de palatabilidade com outras espécies de Callicore realizados com uma ave insetívora (Tyrannus melancholicus) na Amazônia oriental e que mostraram certa impalatabilidade nestas espécies (Pinheiro \& Martins, 1992; Pinheiro, 1996).

Em segundo lugar, os resultados envolvendo as características populacionais destas espécies também sugerem que estas borboletas não formam um caso clássico de mimetismo Batesiano. De acordo com a teoria de Bates (1862) espécies modelo geralmente apresentam tamanhos populacionais maiores que espécies de mímicos, permitindo assim que predadores os encontrem primeiro e aprendam a evitá-los antes de encontrarem os mímicos Batesianos.

Nossos resultados mostram que $S$. galanthis e C. sorana apresentam um padrão semelhante de dinâmica populacional, ambas restritas à estação seca, um resultado também encontrado por Freire Jr. (2015) para vários outros Biblidinae e Charaxinae encontrados no Brasil central, e picos populacionais no meio desta estação (em agosto de 2014 e 2015). Além disto, as estimativas de tamanhos populacionais baseados em dados de marcação e recaptura nos anos de 2014 e 2015 também mostraram tamanhos bem próximos entre si, mostrando que esta premissa do mimetismo Batesiano não se aplica a este par de espécies. Além destas características $S$. galanthis e $C$. sorana também apresentaram várias semelhanças no tempo de residência na área de estudos e na dispersão de indivíduos na área de estudos (a única diferença significativa encontrada entre fêmeas destas espécies foi observada na proporção de recapturas na mesma subárea ou em diferentes subáreas da marcação original, mas a comparação envolvendo as distâncias lineares entre sucessivas recaptura também não mostrou diferença significativa neste caso). 
Em vista dos argumentos expostos acima, as evidências encontradas neste estudo indicam que $S$. galanthis e $C$. sorana não constituem um caso clássico de mimetismo Batesiano ou Mülleriano, mas podem constituir um caso de mimetismo de escape. Este tipo de mimetismo, entretanto, tem sido pouco investigado, provavelmente devido às dificuldades encontradas para observá-lo em espécies no ambiente natural ou reproduzi-lo em condições de laboratório. Alguns experimentos realizados com aves insetívoras têm demonstrado que estes animais de fato aprendem a evitar presas que não conseguem capturar, de forma semelhante às aves que aprendem a evitar presas impalatáveis (Gibson, 1974 e 1980; Hancox \& Allen, 1991). Estes experimentos, entretanto, são criticados por Brower (1995) que afirma que os animais testados não foram capazes de manter em sua memória os padrões de cor de presas que escapam de seus ataques e rapidamente voltaram a atacá-las, o que contrasta com a memória de longa duração observada em aves que aprendem a evitar presas com defesas químicas. Utilizando modelos matemáticos Ruxton et al. (2004) sugeriram que a evolução do mimetismo de escape é possível, mas altamente improvável. Apesar destas contradições vários exemplos de casos de mimetismo de escape em borboletas (Srygley, 1994 e 1999; Pinheiro \& Freitas, 2014; Pinheiro et al., 2016), vários outros insetos (Hespenheide, 1973; Balgooyen, 1997; Holm \& Kirsten, 1979; Bristow, 1981; Vannin \& Guerra, 2012) e mesmo em aves (Baker \& Parker, 1979) têm sido relatados.

Evidências adicionais indicando que $S$. galanthis e $C$. sorana formam um mimetismo de escape foram também obtidas (1) no tipo de marcas encontradas (todas do tipo "tears", que indicam que as borboletas foram capturadas, mas conseguiram escapar perdendo apenas pequenos pedaços das asas durante o ataque) e (2) na alta incidência de marcas de bicadas encontradas nestas borboletas (especialmente no caso de marcas assimétricas que mostram que foram atacadas no ar e, portanto, exibindo os padrões de coloração aposemáticos para os seus predadores), que indicam uma grande capacidade de fuga de ataques de aves insetívoras. O fato de borboletas mais velhas apresentarem maior número de ataques do que indivíduos jovens ou de idade intermediária encontrado em ambas as espécies também reforça esta grande capacidade de escapar de ataques de predadores. Além disto, as comparações realizadas no número de marcas assimétricas entre indivíduos do mesmo sexo e idade sugerem que $S$. galanthis e $C$. sorana são igualmente atacadas e apresentam habilidades semelhantes para escapar dos ataques de predadores (diferenças significativas foram encontradas apenas no caso de machos velhos e de fêmeas intermediárias) o que poderia 
indicar que estas espécies formam um caso de mimetismo Mülleriano de escape. Esta possibilidade, entretanto, precisaria ser comprovada através de estudos complementares. 


\section{CONCLUSÕES}

Os resultados obtidos neste trabalho demonstram que $S$. galanthis e $C$. sorana não constituem um caso clássico de mimetismo Batesiano ou Mülleriano, tendo em vista que ambas as espécies são palatáveis e apresentam fortes semelhanças nos tamanhos e outras características populacionais investigadas. Entretanto, S. galanthis e C. sorana podem constituir um caso de mimetismo de escape, que pode ser corroborado pelo grande número de marca de bicadas assimétricas encontrado nessas espécies e que indicam uma grande capacidade destas borboletas de escaparem de ataques de predadores. 


\section{REFERÊNCIAS BIBLIOGRÁFICAS}

BAKER, R. R. \&, PARKER G. A. 1979. The evolution of bird coloration. Philosophical Transactions of the Royal Society Lond Biological Sciences, 287:63-130.

BALGOOYEN, T. G. 1997. Evasive mimicry involving a butterfly model and a grasshopper mimic. American Midland Naturalist, 137: 183-187.

BATES, H. W. 1862. Contributions to an insect fauna of the Amazon valley. Transactions of the Linnean Society of London, 23: 495-566.

BOWERS, M. D. 1993. Ecological and evolutionary constraints on foraging. In: Catterpillars. N. E Stamp \& N. E Casey (eds). Chapman and Hall, 331-338.

BOYDEN, T. C. 1976. Butterfly palatability and mimicry: experiments with Ameiva lizards. Evolution, 30: 73-81.

BRISTOW, C. R. 1981. A revision of the brassoline genus Catoblepia (Lepidoptera, Rophalocera). Zoological Journal of the Linnean Society, 72: 117-163.

BROWER, L. P. 1984. Chemical defence in butterflies. In: The Biology of Butterflies. R. I. VaneWright \& P. R. Ackery (eds.), Academic Press, 109-134.

BROWER, L. P. 1995. Understanding and misunderstanding the migration of the monarch butterfly (Nymphalidae) in North America. Journal of the Lepidopterists' Society, 49: 304-85.

BROWN., K. S. \& MIELKE, O. H. H. 1967. Lepidoptera of the Central Brazil Plateau. I. Preliminary list of Rhopalocera: Introduction, Nymphalidae, Libytheidae. Journal of the Lepidopterists' Society, 21: 77-106.

BROWN, K. S. 1984. Adult-obtained pyrrolizidine alkaloid defend ithominae butterflies against a spider predator. Nature, 309: 707-709.

DeVRIES, P. J. 1987.The butterflies of Costa Rica and their natural history: Papilionidae, Pieridae, Nymphalidae. Princeton University Press, p. 327. 
DINIZ, I.R. \& MORAIS, H.C. 1995. Larvas de Lepidopterae suas plantas hospedeiras em um cerrado de Brasília, DF, Brasil. Revista Brasileira de Entomologia, 39 (4): 755 770.

EHRLICH, P. R. \& EHRLICH, A. H. 1982. Lizard predation on tropical butterflies. Journal of the Lepidopterists' Society, 36 (2): 148-152.

EMERY, E. O., BROWN, K. S., PINHEIRO, C. E. G. 2006. A fauna de borboletas (Lepidoptera, Papilionoidea) do Distrito Federal. Revista Brasileira de Entomologia, 50 (1): 85-92.

FRANCINI, R. B. 2010. Métodos para estudar ecologia de populações de borboletas. Santos, SP, E-book publicado pelo autor, $201 \mathrm{p}$.

FREIRE, G. B. Jr \& DINIZ, I. V. 2015. Temporal dynamics of fruit-feeding butterflies (Lepidoptera: Nymphalidae) in two habitats in a seasonal Brazilian environment. Florida Entomologist, 98 (4): 1207-1216.

FREITAS, A.V. L., FRANCINI, R. B. \& BROWN Jr., K. S. 2003. Insetos como indicadores ambientais. In: Métodos de estudos em biologia da conservação e manejo da vida silvestre. (L. Cullen Jr., R. Rudran \& C. Valladares-Pádua, org.). Editora da UFPR, Fundação O Boticário de Proteção à Natureza, cap.5, p.125-151.

FRYER, J. G. F. 1913. Field-observations on the enemies of butterflies in Ceylon. Proceedings of the Zoological Society of London, 83 (2): 613-619.

GIBSON, D. O. 1974. Batesian mimicry without distastefulness. Nature, 250: 77-79.

GIBSON, D. O. 1980. The role of escape in mimicry and polymorphism: In. The response of captive birds to artificial prey. Biological Journal of the Linnean Society, 14: 201-214.

HANCOX, A. P \& ALLEN, J. A. 1991. A simulation of evasive mimicry in the wild. Journal of Zoology, 223 (1): 9-13.

HESPENHEIDE, H. A. 1973. A novel mimicry complex: beetles and flies. Journal of Entomology A, 48: 49-56. 
HOLM, E. \& KIRSTEN, J. F. 1979. Preadaptations and speed mimicry among Namib desert scarabaeids with orange elytra. Journal of Arid Environments, 2: 263-271.

MÜLLER, F. 1879. Ituna and Thyridia: a remarkable case of mimicry in butterflies. Proceedings of the Royal Entomological Society of London, 20-29.

ODENDAAL, F. J., RAUSHER, M. D., BENREY, B., NUNEZ-FARFAN, J. 1987. Predation by Anolis lizards on Battus philenor raises questions about butterfly mimicry systems. Journal of the Lepidopterists' Society, 41:141-144.

PINHEIRO, C. E. G. 1996. Palatability and escaping ability in Neotropical butterflies: tests with wild Kingbirds (Tyrannus melancholicus, Tyrannidae). Biological Journal of the Linnean Society, 59: 351-365.

PINHEIRO, C. E. G. 2007. Asynchrony in daily activity patterns of butterfly models and mimics. Journal of Tropical Ecology, 23: 119-123.

PINHEIRO, C. E. G. 2011. On the evolution of warning coloration, Batesian and Müllerian mimicry in Neotropical butterflies: the role of jacamars (Galbulidae) and tyrantflycatchers (Tyrannidae). Journal of Avian Biology, 42: 277-281.

PINHEIRO, C. E. G., FREITAS, A. V. L. 2014. Some possible cases of escape mimicry in neotropical butterflies. Neotropical Entomology, 43: 393-398.

PINHEIRO, C. E. G., FREITAS, A. V. L., CAMPOS, V. C., DeVRIES, P.J.; PENZ, C. M. 2016. Both Palatable and Unpalatable Butterflies Use Bright Colors to Signal Difficulty of Capture to Predators. Neotropical Entomology.

PINHEIRO, C. E. G., MARTINS, M. Palatability of seven butterfly species (Nymphalidae) to two tyrant flycatchers in Brazil. Journal of the Lepidopterists' Society, 46 (1): 77-79.

PINHEIRO, C. E. G.; ORTIZ, J. V. C. 1992. Communities of fruit-feeding butterflies along a vegetation gradient in central Brazil. Journal Biogeography, 19: 505-511.

RIBEIRO, J. F.; WALTER, B. M. T. Fitofisionomias do bioma Cerrado: ampliado. In: SANO, S. M.; ALMEIDA, S. P. (ed.). Cerrado: ambiente e flora. Planaltina: Embrapa Cerrados, $2^{\circ}$ edição. 556 p. 
RUXTON, G. D., SPEED, M., SHERRATT, T. N. 2004. Evasive mimicry: when (if ever) could mimicry based on difficulty of capture evolve? Proceedings of the Royal Entomological Society of London B, 271: 2135-2142.

SKELHORN, J., ROWLAND, H. M., SPEED, M. P.; RUXTON, G. D. 2010. Masquerade: camouflage without crypsis. Science, 327:51-51.

SRYGLEY, R.B., CHAI, P. 1990. Flight morphology of Neotropical butterflies: palatability and distribution of mass to the thorax and abdomen. Oecologia, 84: 491-499.

SRYGLEY, R. B. 1994. Locomotor mimicry in butterflies? The associations of positions of centres of mass among groups of mimetic, unprofitable prey. Philosophical Transactions of the Royal Society Lond Biological Sciences, 343:145-155.

SRYGLEY, R. B. 1999. Incorporating motion into investigations of mimicry. Evololutionary Ecology, 13:691-708.

TRIGO, J. R. 2000. The chemistry of antipredator defense by secondary compounds in neotropical Lepidoptera: facts, perspectives and caveats. Journal of the Brazilian Chemistry Society, 11: 551-561.

UEHARA-PRADO, M. 2003. Efeitos da fragmentação florestal na guilda de borboletas frugívoras do Planalto Atlântico Paulista. 2003. Dissertação (Mestrado em Ecologia) - Instituto de Biologia, Universidade Estadual de Campinas, Campinas. $144 \mathrm{p}$.

VANNIN, S. A., GUERRA, T. J. 2012. A remarkable new species of flesh-fly mimicking weevil (Coleoptera: Curculionidae: Conoderinae) from Southeastern Brazil. Zootaxa, 3413 (3413): 55-63.

van SOMEREN, V. G. L., JACKSON, T. H. E. 1959. Some comments on protective resemblance amongst African Lepidoptera (Rhopalocera). The Journal of the Lepidopterists' Society, 13: 121-150.

VASCONCELLOS-NETO, J. \& LEWINSOHN, T. M. 1984. Discrimination and release of unpalatable butterflies by Nephila clavipes, a neotropical orb-weaving spider. Ecological Entomology, 9: 337-344. 